\title{
IMPORTÂNCIA DO COMPLEXO 2 DA VIA mTOR (mTORC2) NAS FUNÇÕES EFETORAS E NO METABOLISMO DOS NEUTRÓFILOS EM MODELO EXPERIMENTAL DE SEPSE
}

\author{
Tese apresentada ao programa de Pós-graduação \\ em Imunologia do Instituto de Ciências \\ Biomédicas da Universidade de São Paulo para \\ obtenção do Título de \\ Doutora em Ciências. \\ Área de concentração: Imunologia \\ Orientador: Prof. Dr. Niels Olsen Saraiva Câmara \\ Versão Original
}

São Paulo 


\section{RESUMO}

Naffah-de-Souza, C. Importância do complexo 2 da via mTOR (mTORC2) nas funções efetoras e no metabolismo dos neutrófilos em modelo experimental de sepse [Tese (Doutorado em Imunologia)]. São Paulo: Instituto de Ciências Biomédicas, Universidade de São Paulo, 2019.

Os neutrófilos são importantes células do sistema imune inato e a primeira linha de resposta durante um processo inflamatório. Suas propriedades e funções, assim como seu metabolismo, bastante estudados no passado, ganharam uma nova perspectiva com o advento de uma nova área do conhecimento: o imunometabolismo. Com isso, o estudo da via metabólica mTOR se evidenciou nas células imunes. Porém, a participação dessa via nas funções efetoras e no metabolismo dos neutrófilos ainda é pouco esclarecida. De maneira mais restrita, a importância do complexo mTORC2 nessas células é ainda menos explorada, pois não há um inibidor específico desse complexo. Sabendo-se que a via mTOR se conecta com a via PI3K pela quinase AKT, formulamos a hipótese de que a deleção de mTORC2 prejudicaria as funções efetoras dos neutrófilos, uma vez que a PI3K é importante para a quimiotaxia, fagocitose, degranulação e para o burst oxidativo dos neutrófilos. Dessa forma, usando animais deficientes ou não em mTORC2 ativado (LysMRic $\Delta / \Delta$ ou LysMRic fl/fl) apenas nas células mieloides, nós investigamos o papel desse complexo sob as funções efetoras e o metabolismo dos neutrófilos. Além disso, verificamos o impacto dessa deleção em modelo experimental de sepse. Ao avaliarmos o estado de ativação da via mTOR, observamos que o estímulo com LPS é capaz de ativar mTORC2 e que a ausência de mTORC2 ativo nos neutrófilos diminui a fosforilação da AKT 308 frente ao LPS. Quanto às funções efetoras dos neutrófilos, verificamos que a ausência de mTORC2 ativo prejudica a quimiotaxia frente ao fMLP, mas não aparenta interferir na capacidade fagocítica dessas células. No entanto, a capacidade microbicida está reduzida nesses neutrófilos. Identificamos que o prejuízo no killing da $E$. coli é devido a uma menor produção de NO, superóxido e, principalmente, HOCl. Possivelmente, a menor produção de $\mathrm{HOCl}$ tenha sido responsável também pela menor produção de NETs nos neutrófilos sem mTORC2 ativo. Ao avaliarmos o metabolismo desses neutrófilos, observamos que na ausência de mTORC2 os neutrófilos são mais glicolíticos frente aos estímulos com fMLP ou LPS, porém a captação de glicose desses neutrófilos é menor quando comparada ao controle com a via intacta. Posteriormente, o impacto da deficiência de mTORC2 em neutrófilos foi avaliado in vivo em modelo de sepse induzida por E. coli. Neste caso, não observamos diferença na sobrevida dos animais, mas os parâmetros bioquímicos e da calorimetria indireta sugerem um quadro de sepse mais grave nos animais LysMRic $\Delta / \Delta$. Além disso, a carga bacteriana nos órgãos-alvo da sepse foi maior nos animais LysMRic $\Delta / \Delta$, corroborando nossos achados in vitro. Assim, concluímos que a deficiência de mTORC2 nos neutrófilos implica em uma menor produção de oxidantes, principalmente o $\mathrm{HOCl}$, o que leva a um prejuízo na capacidade microbicida e na formação das NETs nesses neutrófilos.

Palavras-chave: Neutrófilos. Via mTOR. mTORC2. Imunometabolismo. Sepse. 


\begin{abstract}
Naffah-de-Souza, C. Role of mTOR complex 2 (mTORC2) in the neutrophil's effector function and metabolism during a sepsis model. [Tese (Doutorado em Imunologia)]. São Paulo: Instituto de Ciências Biomédicas, Universidade de São Paulo, 2019.

Neutrophils are the first line of defense in the innate arm of the immune system. Their functions and metabolism were well explored in the past. However, a new research field, the immunometabolism, brought new perspectives to neutrophil's functional properties. Besides, the metabolic pathway mTOR, also became spotlighted with the immunometabolism emergence. Nevertheless, the role of mTOR pathway, mainly the mTORC2, in neutrophils is not clear. It is well known that mTOR pathway is linked to PI3K via AKT. Therefore, we hypothesized that the mTORC2 deletion in neutrophils would impair their effector functions once PI3K is important to neutrophil's chemotaxis, phagocytose, degranulation and oxidative burst. In this sense, we used a myeloid-specific Rictor deleted mice (inactive mTORC2) to investigate the role of mTORC2 in neutrophil's effector functions and metabolism. Moreover, we evaluated the impact of Rictor deletion in a mouse sepsis model. We observed that LPS can activate mTORC2 and the absence of active mTORC2 decreases the AKT ${ }^{\mathrm{T} 308}$ phosphorylation upon LPS stimulation. We demonstrated that inactive mTORC2 impairs neutrophil's chemotaxis upon fMLP stimulation, and apparently does not interfere with its phagocytic capacity. However, the neutrophil's microbicidal capacity is clearly compromised due to an impairment in NO, superoxide, but mainly in $\mathrm{HOCl}$ production. Possibly, the decrease in $\mathrm{HOCl}$ production affected the NETs formation. Regarding the neutrophil's metabolism, we observed that when mTORC2 is absent the neutrophils are more glycolytic upon fMLP or LPS stimulation, but their glucose uptake is lower than the active mTORC2-neutrophils. After, we investigated the impact of the Rictor deletion in a E. coli-induced sepsis model. Although we did not see statistic difference in the survival curve, the glycemia, urea and indirect calorimetry suggest a poor sepsis outcome in the LysMRic $\Delta / \Delta$ animals. Besides, the bacterial burden was increased in the LysMRic $\Delta / \Delta$, corroborating our in vitro results. Therefore, we conclude that mTORC2 absence in neutrophils implies in a decrease in oxidants production, mainly $\mathrm{HOCl}$, leanding to an impairment in the microbicidal capacity and NETs formation.
\end{abstract}

Key-words: Neutrophils. mTOR pathway. mTORC2. Immunometabolism. Sepsis. 


\section{INTRODUÇÃO}

\subsection{Sistema imune: Visão geral}

O sistema imune possui duas principais linhas de resposta a um agente causador de estresse: a imunidade inata e a adaptativa, sendo que a imunidade inata é a primeira linha de reconhecimento do nosso organismo. Ela é composta, principalmente, por barreiras físicas e químicas, fagócitos, que compreendem os neutrófilos e macrófagos, células Natural Killer (NK) e células dendríticas (DCs) (1-3). Estas são classicamente conhecidas por fazerem a comunicação entre a resposta imune inata e a adaptativa (4).

Composta por células capazes de reconhecer e responder diretamente aos padrões moleculares associados a patógeno, do inglês Pathogen-Associated Molecular Patterns (PAMPs), como o lipopolisacarídeo (LPS), por exemplo, a resposta imune inata é reconhecida por sua ação rápida. 0 reconhecimento dos PAMPs se dá através dos padrões de reconhecimento de padrão, do inglês Patter Recognition Receptors (PRRs) presentes nas células da imunidade inata, como o receptor do tipo Toll, do inglês Toll-like receptor (TLR) 4, capaz de reconhecer o LPS.

Após o reconhecimento e ativação das células da imunidade inata, as citocinas presentes no microambiente inflamatório, juntamente com a apresentação dos antígenos aos linfócitos $\mathrm{T}$ pelas $\mathrm{DCs}$, orquestram a resposta adaptativa (4). Composta, principalmente, de linfócitos $\mathrm{T}$ citotóxicos ( $\left.\mathrm{CD} 8^{+}\right)$, linfócitos $\mathrm{T}$ auxiliares $\left(\mathrm{CD} 4^{+}\right)$, linfócitos B e anticorpos, a imunidade adaptativa é capaz de montar uma resposta mais específica e eficiente para o restauro da homeostasia $(1,5)$. Embora a imunidade adaptativa tenha uma especificidade maior quando comparada à imunidade inata, esta é de extrema importância para os seres vivos multicelulares (6). Os fagócitos são parte fundamental da imunidade inata, sendo que organismos menos complexos, que não possuem imunidade adaptativa, dependem destas células para reconhecer de forma eficiente os patógenos (7). Dentre as células capazes de fagocitar microrganismos, os neutrófilos encontram destaque por representarem a maioria das células circulantes nos seres humanos, serem as primeiras células a chegarem ao foco inflamatório e capazes de reconhecer uma gama de microrganismos, assim como responder prontamente, de forma a conter os patógenos (8). 


\subsection{Neutrófilos: origem e funções}

Os neutrófilos são oriundos de progenitores mieloides da medula óssea, correspondendo entre 55 a $60 \%$ do total de células na corrente sanguínea dos seres humanos (8). Os neutrófilos são chamados de fagócitos profissionais devido à sua capacidade fagocítica, visto que seus grânulos não possuem afinidade nem pelo corante ácido, eosina, nem pelo corante básico, a hematoxilina $(3,9)$.

Desde a sua descoberta, os neutrófilos são considerados potentes células inflamatórias sendo cruciais frente a uma infecção. Além disso, elas enviam sinais por meio de citocinas e quimiocinas, recrutando outras células para o local inflamado (5). No entanto, o dano tecidual ocasionado pela ativação exacerbada dos neutrófilos fez com que suas funções efetoras fossem vistas como pouco refinadas (6). Atualmente, os avanços nos estudos da imunidade inata têm modificado o cenário da biologia dos neutrófilos, incluindo suas propriedades e funções (10).

Por possuírem um tempo de vida relativamente curto, os pesquisadores acreditavam, até então, que os neutrófilos estavam presentes apenas na fase aguda da resposta inflamatória. No entanto, pesquisas mais recentes apontam que estas células podem moldar a resposta imune através da comunicação com macrófagos, células dendríticas (DCs) e células da imunidade adaptativa por meio de interação celular direta (célula-célula) ou mediadores solúveis $(11,12)$. Além disso, os neutrófilos fazem uso de diferentes estratégias para eliminar a eliminação dos patógenos, algumas delas descritas mais recentemente, como a formação das redes de cromatina, as NETs (do inglês Neutrophil Extracellular Traps) (13). A diversidade de substâncias presentes nos grânulos destas células também tem sido melhor estudada, bem como sua a capacidade microbicida e quimiotática (3) (Figura 1). 


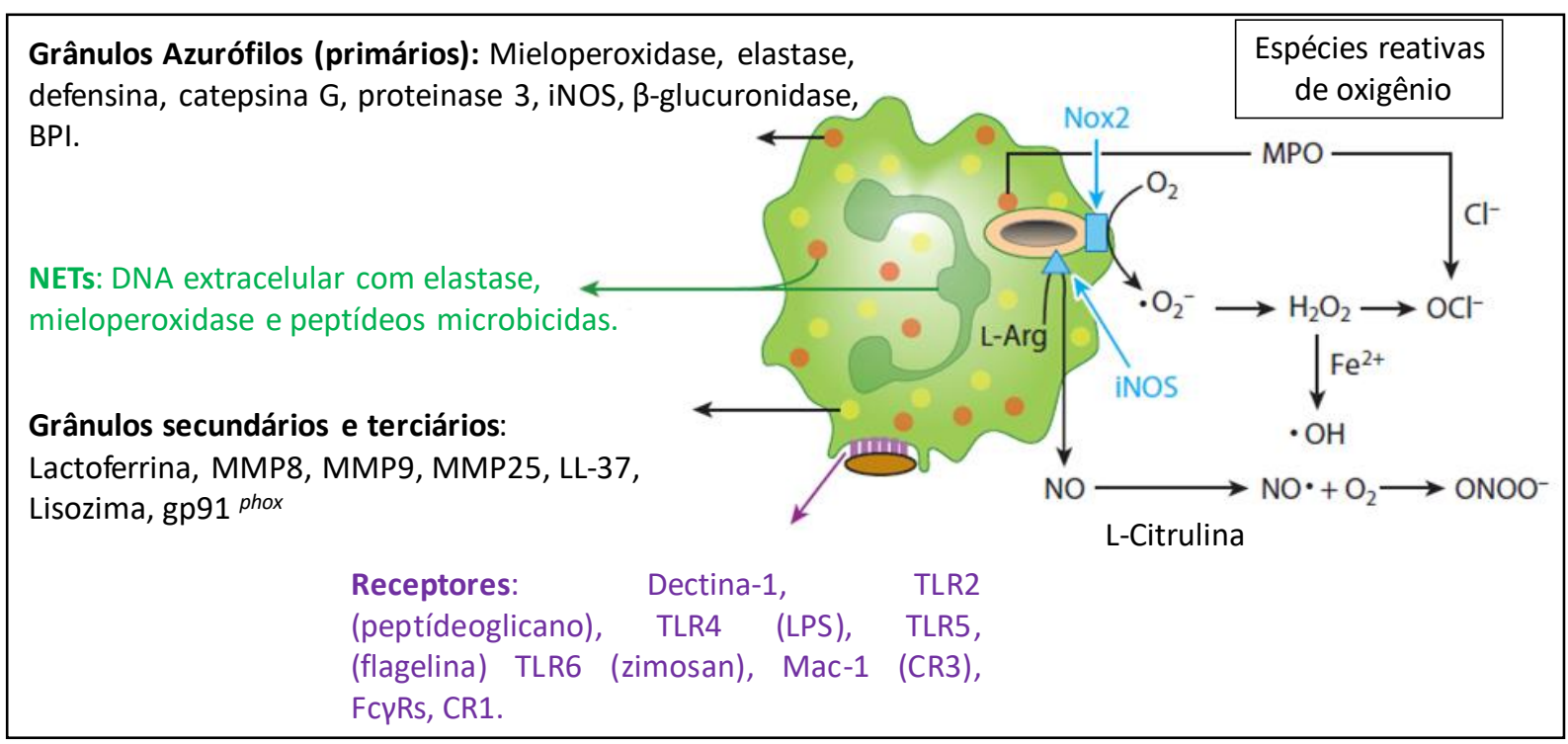

Figura 1. Funções efetoras dos neutrófilos. Após ativação, os neutrófilos desempenham diversas funções efetoras. Algumas delas são dependentes do conteúdo presente em seus grânulos, que podem ser divididos em azurófilos ou primários, secundários e terciários. Além dos grânulos, os neutrófilos possuem diversos receptores de membranas, produzem espécies reativas de oxigênio e nitrogênio e formam "armadilhas" (NETs) através da secreção de DNA e elastase para capturar patógenos. Adaptado de (6).

\subsubsection{Quimiotaxia}

O processo de quimiotaxia dos neutrófilos, ou migração guiada, direciona essas células para o foco inflamatório por meio de quimioatraentes, como o Formyl-MethionylLeucyl-Phenylalanine (fMLP) ou a quimiocina CXCL8 (6) . Esse processo envolve uma série de mecanismos moleculares para que ocorra o rearranjo do citoesqueleto e da membrana plasmática, permitindo a polarização da actina e, consequente, motilidade dos neutrófilos (14). Embora a quimiotaxia dos neutrófilos seja bastante estudada, o processo coordenado de formação de protrusões na parte anterior da célula, os pseudópodes, juntamente com a retração na sua parte posterior, chamada de uropódio, ainda precisa ser melhor esclarecida $(15,16)$. As moléculas e vias envolvidas na motilidade dos neutrófilos são diversas. As mais estudadas são a Ras-related C3 botulinum toxin substrate (Rac), Phosphatidylinositol 3-kinase (PI3K), gerando Phosphatidylinositol (3,4,5)trisphosphate (PIP3) e Cell division control protein 42 homolog (Cdc42), que agem na porção anterior dos neutrófilos (15). A ativação da Rac induz a polarização da actina e a formação dos pseudópodes (15). O PIP3 age por meio de retroalimentação positiva com a Rac para polarizar a dinâmica da actina na parte anterior da membrana, contribuindo para a formação das protrusões e motilidade (15). Já a Cdc42 tem a atividade de inibir a proteína Ras homolog gene family, member $A$ (RhoA) na parte anterior da célula, uma vez que a RhoA age no uropódio. Além disso, a Cdc42 controla a redistribuição da Wiskott- 
Aldrich Syndrome protein (WASP), importante para a redistribuição da integrina CD11b no uropódio (15). Além da WASP, outras proteínas desempenham um papel crucial no uropódio. São elas, a RhoA, a proteína quinase associada à RhoA (do inglês Rho- $A$ associated protein kinase ROCK), miosina II e PI(4,5)P2 (15). As três primeiras agem por meio de retroalimentação positiva, estabilizando o uropódio, enquanto a RhoA estabiliza o mesmo por inibir a Rac (15). Já a PI(4,5)P2 tem um papel na retração do uropódio, gerando, assim, a força necessária para a motilidade dos neutrófilos. A WASP, por sua vez, controla a redistribuição da integrina CD11b no uropódio dos neutrófilos (15). Essa redistribuição é importante para a contração da miosina, contribuindo para a estabilidade do uropódio. Mais recentemente foi verificado que a via mTOR, por meio do seu complexo 2 (mtORC2), tem ação na polarização da actina e também age na miosina II, via RhoA e adenosina monofosfato cíclico (AMPc), contribuindo para a retração da parte posterior da célula $(17,18)$.

Além da complexidade e envolvimento de diferentes moléculas e vias de sinalização que levam à motilidade dos neutrófilos, a ativação do endotélio durante um processo inflamatório é de crucial importância para que essas células cheguem ao local inflamado (6). Ao expressar E-selectinas e ligantes de integrinas (ICAM-1 e VCAM-1, do inglês Intercellular Adhesion Molecule 1 e Vascular Cell Adhesion Molecule 1, respectivamente), o endotélio permite e direciona o rolamento e a transmigração dos neutrófilos da corrente sanguínea para o foco inflamatório (6).

Após a transmigração, os neutrófilos se ativam completamente e podem fagocitar e eliminar patógenos por meio da produção de espécies reativas de oxigênio e nitrogênio, do inglês reactive oxygen species (ROS) e reactive nitrogen species (RNS), respectivamente, degranulação e formação das NETs (6). 


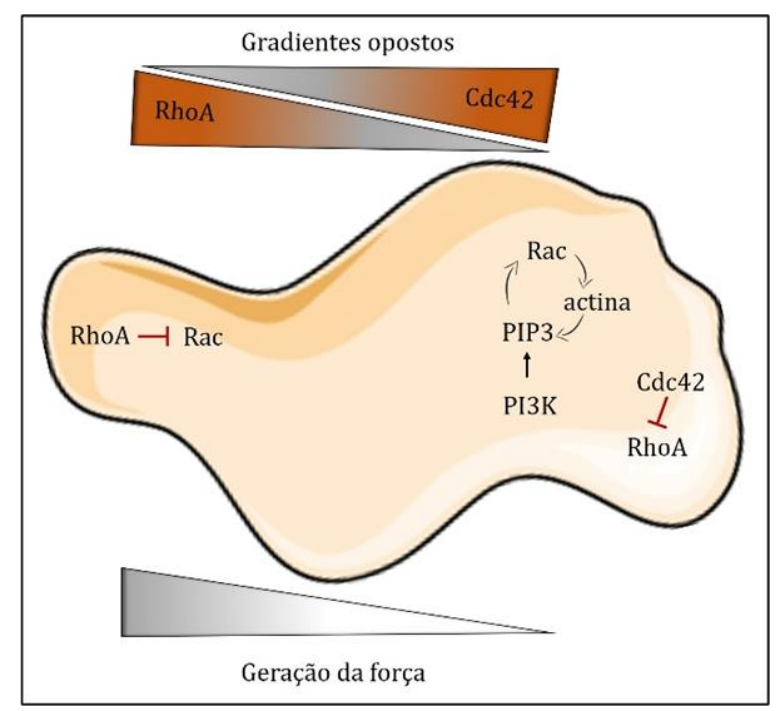

Figura 2. Processo de formação dos pseudópodes e uropódio nos neutrófilos. Diferentes moléculas estão envolvidas no processo de migração quimiotática dos neutrófilos. As moléculas Rac, PIP3 e Cdc24 estão envolvidas com a polimerização dos filamentos de actina na parte anterior dos neutrófilos. A molécula RhoA está envolvida no processo de polimerização de actina e miosina II na parte posterior dessas células (uropódio), onde se concentra a força para impulsionar as células para frente. Adaptado de (15)

\subsubsection{Degranulação}

Os neutrófilos são providos de diferentes grânulos que são formados durante a maturação dessas células $(19,20)$. Eles são divididos baseados em sua densidade e composição e constituem um importante reservatório de proteínas microbicidas, proteases e componentes importantes para o burst oxidativo (21). Os grânulos podem ser divididos em azurófilos ou primários, secundários, terciários e secretórios (Figura 3).

A liberação desses grânulos em compartimentos intracelulares, como os fagossomos, ou para o ambiente extracelular depende de vias de sinalização finamente reguladas, mas ainda não bem elucidadas. Sabe-se que os receptores acoplados à proteína G (GPCRs, do inglês, G protein-coupled receptors), quando ativados, iniciam cascatas de sinalização para movimentação e liberação desses grânulos $(21,22)$. Estudos da década de 2000, indicam que a liberação dos grânulos nos neutrófilos depende da ativação de $\beta$ arrestinas, Rho-GTPases, como a Rac2, e tirosinas quinases e fosfatases $(23,24)$. Além disso, estudos utilizando a linhagem celular de neutrófilo, HL-60, demostraram que a via PI3K é importante para a exocitose dos grânulos (25). Esse processo envolve as etapas de recrutamento e translocação, ancoramento na membrana do fagossomo ou plasmática, por exemplo, e a fusão desses grânulos nas membrana (21). A etapa de recrutamento é dependente do rearranjo do citoesqueleto e montagem dos microtúbulos (26). A etapa da 
fusão é rápida e há a formação de um poro reversível entre a vesícula e o grânulo, de forma a assegurar a completa fusão e liberação do conteúdo granular (21) .

A translocação e exocitose dos grânulos é dependente do aumento de cálcio e adenosina trifosfato (ATP) intracelular (27). Além disso, a reorganização do citoesqueleto de actina é de fundamental importância para que ocorra a exocitose dos grânulos (21). Normalmente, o citoesqueleto forma uma malha em volta da periferia da célula impedindo o encaixe e fusão dos grânulos (21). Portanto, após a ativação, essa malha necessita ser desmontada (concentrada em regiões específicas nos neutrófilos) a fim de facilitar a abertura de locais para que a fusão dos grânulos ocorra (21). Esse rearranjo do citoesqueleto é fundamental não apenas para a exocitose, mas também para a quimiotaxia e fagocitose (21).

\subsubsection{Produção de citocinas}

Embora os neutrófilos expressem uma quantidade de RNA 10-20 vezes menor comparado a outros leucócitos $(28,29)$ e possuam grânulos que armazenam a maioria da maquinaria necessária para desempenhar suas funções, eles também produzem e secretam citocinas e quimiocinas (29). Isso se dá após ativação dessas células por diferentes estímulos contidos no microambiente inflamatório (30) e é regulada por mecanismos que agem a nível transcricional ou pós-transcricional (11, 29-31). Na Figura 3, nota-se a diversidade de citocinas e quimiocinas que os neutrófilos podem secretar. No entanto, é importante ressaltar que a quantidade dessas moléculas, que são produzidas pelos neutrófilos, é significativamente menor comparada aos monócitos/macrófagos ou linfócitos quando em células individuais. Porém, em situações in vivo, devido à grande quantidade de neutrófilos no foco da inflamação, a produção de citocinas e quimiocinas por essas células tem um papel crucial no decorrer do processo inflamatório (29). Essas substâncias tem papel na inflamação, recrutando e ajudando na ativação de células, mas também atuam em contextos anti-inflamatórios, por meio da secreção de TGF- $\beta$, por exemplo. 


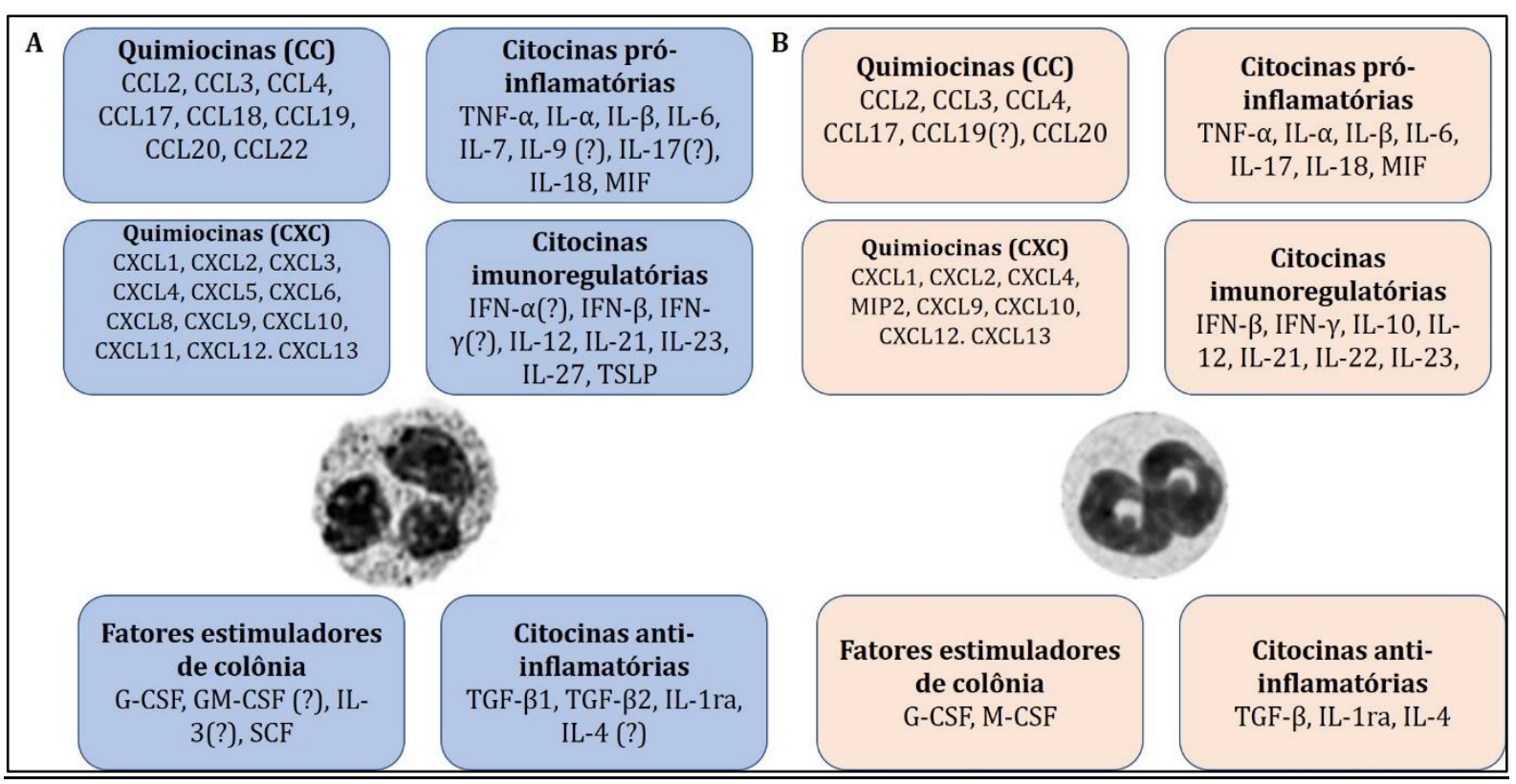

Figura 3. Citocinas que os neutrófilos potencialmente produzem. Tanto os neutrófilos humanos (A), quanto os murinos (B) produzem e secretam diferentes tipos de citocinas e quimiocina, ajudando no processo inflamatório e também na etapa de resolução da inflamação. Adaptada de (29).

\subsubsection{Fagocitose e burst oxidativo}

O processo de fagocitose difere molecularmente entre neutrófilos e macrófagos (32). Para os neutrófilos essa função é crucial para a sua capacidade microbicida. Inicialmente, os patógenos são engolfados, por extensão da membrana plasmática, formando um vacúolo, o fagossomo (32). Este, por sua vez, precisa adquirir propriedades degradativas por meio de um processo complexo chamado de maturação. Isso significa que, após a formação do fagossomo, ele ainda não possui propriedades microbicidas. Por meio da maturação, ele adquire enzimas microbicidas, ATPases vacuolar, e o complexo NADPH oxidase (NOX2) (32). Parte desse processo consiste na fusão dos grânulos primários, secundários e terciários com o fagossomo. Além disso, ocorre também a fusão do lisossomo, formando, então, o fagolisossomo (33). A partir desse momento, o complexo da NOX2 está formado e ativado, permitindo que ocorra o burst oxidativo (34).

O complexo NOX2, nos neutrófilos, compreende a gp91 phox e a p22 ${ }^{\text {phox }}$, presentes na membrana plasmática dessas células. A fagocitose é o principal estímulo para a ativação da NOX2 $(35,36)$. Desta forma, enzimas citoplasmáticas são recrutadas para formar o complexo da NOX2. São elas p40phox, p67phox e p47phox, além da Rac e Rho-GDI (Rho GTP dissociation inhibitor) (35-37). Por meio deste complexo, um elétron é doado, pela oxidação da NADPH a NAD ${ }^{+}$, ao oxigênio molecular capturado do meio, resultando no ânion superóxido. Este ânion é convertido em peróxido de hidrogênio $\left(\mathrm{H}_{2} \mathrm{O}_{2}\right)$ 
espontaneamente ou pela ação da enzima superóxido dismutase (SOD) (38). $\mathrm{O} \mathrm{H}_{2} \mathrm{O}_{2}$, pela ação da enzima mieloperoxidase (MPO), é convertido à ácido hipocloroso (HOCl), por incorporação do ânion cloreto $\left(\mathrm{Cl}^{-}\right)(38,39)$. Estes compostos são cruciais na ação microbicida dos patógenos fagocitados (34, 36, 37, 40) (Figura 4).

Outro importante mecanismo utilizado pelos neutrófilos na eliminação dos microrganismos fagocitados é a produção de RNS (41). Citocinas e produtos microbianos, como o LPS, levam à síntese da enzima óxido nítrico sintase induzida (iNOS) (42). Esta enzima converte L-arginina em L-citrulina na presença de NADPH, liberando óxido nítrico (NO do inglês, nitric oxide) (43) (Figura 1). NO é uma molécula altamente instável capaz de reagir com o superóxido gerando peroxinitrito (ONOO-), um composto com grande potencial oxidativo e microbicida (44-46). Juntamente com as ROS, as RNS aumentam o repertório antimicrobiano que agem nos patógenos fagocitados e também extracelulares, uma vez que essas espécies também são liberadas no microambiente.

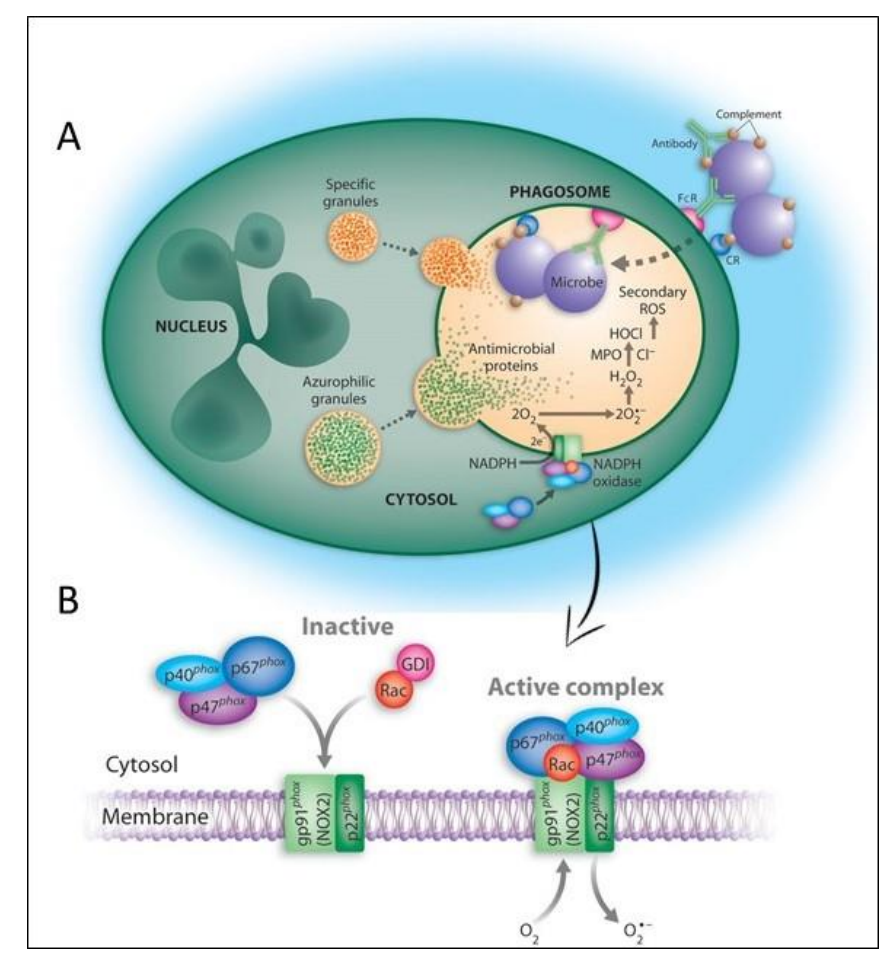

Figura 4. Ativação da NOX2 após fagocitose. Após sinalização celular da fagocitose, os grânulos dos neutrófilos se fundem ao fagolisossomo, liberando enzimas microbicidas (A). Além disso, essa sinalização ativa o complexo da NADPH oxidase, que é composto por várias subunidades: gp91 phox e p22 ${ }^{\text {phox }}$, presentes na membrana, e p40phox, p47phox e p67phox, presentes no citoplasma. As subunidades da NOX2 citoplasmáticas, juntamente com a Rac e a GDI, também presentes no citoplasma, se unem para formar o complexo da NADPH oxidase ativo (B). Adaptada de (37). 


\subsubsection{NETs}

Descobertas em 2004, essa rede composta de cromatina, histonas e enzimas antimicrobianas, como a elastase do neutrófilo (NE) e MPO, é uma importante função efetora dos neutrófilos $(13,47)$. Capazes, não apenas, de reter os patógenos nessa rede de cromatina, as NETs também atuam na morte dos mesmos, pois contem enzimas microbicidas e histonas, que também tem ação antimicrobiana (13). Para liberar as NETs, neutrófilos ativados sofrem um tipo de morte celular que difere da apoptose e necrose (48). Steinberg e Grinstein, em 2007, cunharam o termo "NETose" para a morte do neutrófilo que leva a formação das NETs (49). Elas são independentes de caspase, sofrem decondensamento da cromatina e expansão do núcleo e são dependentes de $\operatorname{ROS}(13,50)$. Até então, dois tipos de NETose são melhores descritos, a dependente e a independente de NOX2. A NETose dependente de NOX2 é o tipo clássico de NETs, verificado após estímulo com PMA, por exemplo. Ela tem início 1 hora após o estímulo e depende de ROS proveniente da NOX2, MPO, da Protein arginine deiminase 4 (PAD4) e NE (51). Essas enzimas translocam para o núcleo, contribuindo para o decondensamento da cromatina e se associando a ela. Após esse processo, ocorre a ruptura da membrana plasmática e a liberação das NETs (51). A NETose independente de NOX2 é mais rápida e dependente de ROS proveniente da mitocôndria (mtROS) (52). Sendo assim, este tipo de NETose é verificado após influxo de cálcio intracelular, que ativa diretamente a mitocôndria, levando à produção de mtROS. Ionóforos de cálcio, como a ionomicina, são ativadores clássicos desse tipo de NETose (52).

Além das NETs dependente e independente da NOX2, em 2009, Yousefi (53) et al. sugeriram um tipo diferente de NETs. Usando microscopia confocal, eles verificaram que os neutrófilos poderiam liberar as redes de DNA sem sofrer NETose . Usando o fator estimulador de colônia granulócito-macrófago (GM-CSF) ou a anafilatoxina, C5a, como estímulo, eles verificaram que esse mecanismo era dependente de DNA mitocondrial e por isso não levava à morte da célula (53). Os mecanismos moleculares envolvidos na formação e liberação das NETs tem sido bastante estudados desde de sua descoberta e algumas moléculas já foram vistas serem cruciais para a formação das NETs, como ROS, MPO e NE $(54,55)$. No entanto, as vias de sinalização que levam a esse fenômeno ainda não são totalmente compreendidas. (Figura 5). 


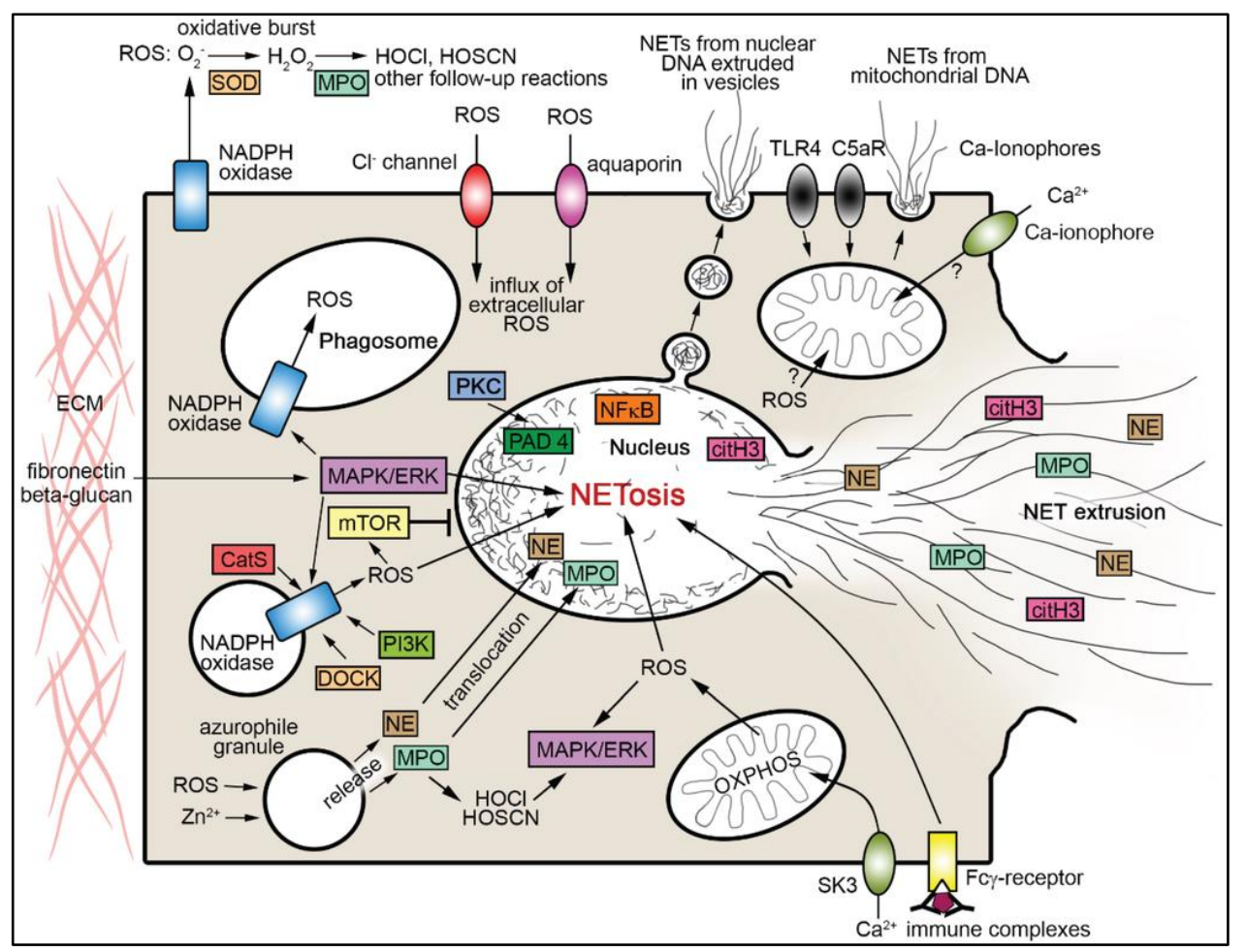

Figura 5. Diferentes mecanismos de NETosis (Clássica e Vital ou Rápida) e moléculas envolvidas. Os diferentes tipos de NETosis são desencadeados de maneiras diferentes. Enquanto a NETosis vital leva a cromatina do núcleo ou da mitocôndria para o meio extracelular em forma de vesículas, a NETosis clássica leva ao rompimento da membrana nuclear e plasmática, liberando as NETs para o meio extracelular as custas da morte do neutrófilo. Muitas são as moléculas e vias de sinalização envolvidas nas NETs, inclusive a via mTOR, mas seu mecanismo molecular ainda não foi totalmente esclarecido. Adaptada de (56).

\subsection{Metabolismo das células imunes: visão geral}

Nos últimos anos, o metabolismo das células do sistema imune tem chamado a atenção dos pesquisadores. Sabendo da importância exercida por essas células para o controle ou progressão de doenças como diabetes, obesidade e câncer, um novo campo de pesquisa se revelou: o imunometabolismo (57). Dessa forma, a compreensão de como as células do sistema imune utilizam energia e como isso afeta suas funções efetoras ganhou destaque nos últimos anos.

As células do sistema imune, precisam produzir energia e sintetizar macromoléculas para desempenhar suas funções. Essa energia é estocada em forma de adenosina trifosfato (ATP) (58). A fonte metabólica mais comumente utilizada para geração de energia nas células do sistema imune é a glicose. A entrada da glicose nas células se dá por meio de transportadores específicos, chamados de transportadores de glicose (GLUT) (59). Existe uma família de diferentes GLUTs presentes nos variados tipos 
celulares. Em células do sistema imune, o tipo mais expresso é o GLUT 1 (60-62). Sendo assim, após a entrada da glicose nas células ocorre uma cascata de 10 reações enzimáticas, em que o primeiro passo é a conversão da glicose em glicose-6-fosfato por meio da hexoquinase. Essas reações ocorrem no citoplasma até a formação do piruvato, com a geração de 2 ATPs (63). 0 piruvato pode ser convertido à lactato, ainda no citoplasma, por meio da enzima lactato desidrogenase (LDH). Isso permite a oxidação do cofator NADH em NAD+, o que permite o restauro do fluxo glicolítico, uma vez que o NAD+ é reduzido na conversão do gliceraldeído-3-fosfato em 1,3-bifosfoglicerato. A produção de lactato era atrelada à chamada via da fermentação do ácido láctico, que ocorria apenas em condições de hipóxia (64). No entanto, em 1923, o médico e fisiologista Otto Heinrich Warburg observou que células tumorais consumiam uma quantidade elevada de glicose, comparada as células normais, mesmo na presença de oxigênio (65). Este fenômeno foi chamado de efeito Warburg. Hoje em dia já se sabe que não apenas as células tumorais, mas células em proliferação, como linfócitos T efetores, ou que demandam energia rápida para executarem suas funções, como os neutrófilos, fazem uso da glicólise aeróbica como via energética de preferência (58).

Outro destino do piruvato, além da conversão em lactato, é a entrada na matriz mitocondrial. Lá ele pode ser oxidado pela piruvato desidrogenase (PDH), formando acetil-CoA, a qual entra no ciclo do ácido tricarboxílico (TCA). 0 ciclo do TCA, por sua vez, além de gerar intermediários metabólicos importantes para a síntese de macromoléculas, gera cofatores essenciais para o abastecimento da cadeia transportadora de elétrons (ETC), como o NADH e o FADH2. A ETC é composta por 4 complexos (I, II, III e IV) mais a ATP sintase. Por meio de reações de oxidação e redução (reações redox) que ocorrem nesses complexos, é gerado um fluxo de elétrons entre os complexos da ETC que, juntamente com o bombeamento de prótons para o espaço intermembranas da mitocôndria, leva à uma diferença de potencial na matriz mitocondrial e no espaço intermembranas $(66,67)$. Essa diferença no gradiente eletroquímico é convertida em energia mecânica, causando a rotação da ATP sintase (68). A energia gerada nessa rotação leva à formação de uma ligação química entre ADP e o fosfato inorgânico (Pi), gerando ATP (68). À eficiente geração de ATP via ETC e ATP sintase damos o nome de fosforilação oxidativa (OXPHOS). Além da geração de grande quantidade de ATP, a ETC também é um importante produtor de ROS mitocondrial (mtROS) (69). Anteriormente vistos como subprodutos da ETC, hoje se sabe que os mtROS são cruciais no direcionamento e função 
das células imunes (70). Nos neutrófilos, por exemplo, eles são importantes na geração de NETs independentes da NOX2 (52).

\subsubsection{Metabolismo dos neutrófilos}

Estudos da década de 1950 destacaram os neutrófilos como células puramente glicolíticas, com pouca ou nenhuma mitocôndria $(71,72)$. Embora a glicólise aeróbica seja a principal fonte energética do neutrófilo, estudos mais recentes mostram que essas células possuem, de fato, poucas mitocôndrias, porém elas formam uma rede no citoplasma e desempenham um papel importante nas funções efetoras e na apoptose dessas células (73-75). Dependendo do seu estado de maturação e dos nutrientes disponíveis, os neutrófilos podem fazer OXPHOS, usando como combustível, principalmente, os ácidos graxos (76).

Além da glicólise aeróbica e da OXPHOS, a via das pentoses fosfato (PPP), é bastante ativa nos neutrófilos (77). Quando a glicose é convertida em glicose-6-fosfato, a glicose-6-fosfato desidrogenase (G6PD) pode direcionar o fluxo de carbono para a PPP. Essa via está associada à produção de NADPH e à biossíntese de nucleotídeos (78). Além disso, a PPP é importante para a regulação dos níveis de lactato no meio. Quando os neutrófilos se encontram em um ambiente com altas concentrações de glicose, para evitar o excesso de produção de lactato, a glicose é desviada para a PPP (77).

O NADPH é um cofator crucial para a geração de ROS via NOX2. É a partir da oxidação do NADPH que elétrons são doados ao oxigênio molecular, iniciando a cascata de produção de ROS e RNS, como já mencionado no sub tópico do burst oxidativo (38). Além disso, a NADPH também é importante para restaurar os níveis de glutationa em sua forma reduzida. A glutationa é um dos principais antioxidantes encontrados nas células (79). Sendo assim, a formação de NADPH também contribui para o estado redox das células.

Outra importante via metabólica nos neutrófilos é a glutaminólise. Esta via é também uma fonte de geração de NADPH via TCA, uma vez que a glutamina leva à geração de malato (80). Este pode ser transportado da matriz mitocondrial para o citoplasma, via um transportador de dicarboxilato. No citoplasma, o malato é convertido à piruvato, levando à geração da NADPH em sua forma reduzida e aumentando o aporte de substrato para a geração de ROS e RNS, via NOX2 (80). 
A importância das vias metabólicas para as ações microbicidas nos neutrófilos está bem estabelecida. A produção de ROS e RNS, por exemplo, está intimamente relacionada com a eliminação dos patógenos fagocitados ou mesmo extracelulares $(34,36,37,40)$. Além disso, mais recentemente foi descrita a dependência de ROS, via NOX2, ou mtROS para a produção das NETs $(13,50)$, outro mecanismo microbicida de fundamental importância nos neutrófilos. No entanto, os mecanismos moleculares que conectam as vias metabólicas às ações microbicidas ainda não estão totalmente esclarecidos. Sabe-se que o fator de transcrição HIF-1 $\alpha$ tem um papel importante nesse contexto. Ele atua no metabolismo glicolítico dos neutrófilos, aumentando a expressão de fatores importantes para via glicolítica, como o transportador Glut-1 e a enzima fosfoglicerato quinase 1 (PGK1) (81). Além disso, o HIF-1 $\alpha$ controla a expressão de fatores microbianos, como os peptídeos antimicrobianos relacionados à catelicidina, NOS2, a NE e catepsina G, por exemplo (82). A ativação do eixo mTORC1-HIF-1 $\alpha$ também foi visto no contexto das NETs, aumentando sua produção (83). No entanto, os mecanismos moleculares que relacionam a via mTOR às funções efetoras dos neutrófilos em geral não são claros, sendo necessário mais estudos nessa área.

\subsection{Via mTOR}

A proteína alvo da rapamicina em mamíferos (mTOR) faz parte de uma via de sinalização que participa de diversas funções celulares como metabolismo, crescimento, sobrevivência, envelhecimento e memória (84). mTOR é uma serina-treonina quinase conservada evolutivamente com peso molecular de $290 \mathrm{kDa}$. Seu nome tem como origem o seu inibidor rapamicina (RAPA), que foi inicialmente isolado de bactérias do solo de Rapa Nui, na Ilha de Páscoa. A RAPA, também conhecida como Sirolimus® e Everolimus®, forma um complexo com a proteína ligante 12 de FK506 (FKBP12) que permite a inibição de mTOR. A via mTOR pode ser ativada de diversas formas, dentre elas a variação da razão ATP:AMP via proteína quinase ativada por AMP (AMPK), por insulina, fatores de crescimento 1 do tipo insulina (IGF-1), por amino ácidos via Rag GTPases e Wnt ativando a via glicogênio-sintase-quinase 3 (GSK3). Receptores do sistema imune também podem ativar mTOR como, por exemplo, receptores de linfócitos T (TCR) e B (BCR), receptores de citocinas e TLR (85). Todos estes são capazes de ativar proteínas quinases, como a PI3K, por exemplo. Após ativada, a PI3K é recrutada para a membrana plasmática e fosforila o fosfatidilinositol $(4,5)$-bifosfato (PIP2) para gerar fosfatidilinositol $(3,4,5)$ - 
trifosfato (PIP3). Este, por sua vez, recruta a serina-treonina quinase AKT para a membrana plasmática, permitindo a fosforilação da AKT ${ }^{\mathrm{T} 308}$ pela PDK1 e da AKT ${ }^{\mathrm{S} 73}$ pelo mTORC2 (86). Dessa forma, a AKT alcança sua ativação máxima e é capaz de regular processos metabólicos envolvendo crescimento e sobrevivência celular (87). A AKT fosforila o complexo tuberosa esclerosa (TSC) 2 diminuindo a inibição sobre Rheb que ativa o complexo 1 da via mTOR (mTORC1) (88) (Figura 4).

A molécula mTOR participa de dois complexos, o primeiro chamado de mTORC1, do qual também fazem parte a proteína regulatória associada de mTOR (Raptor), a proteína adaptadora mLST8 (do inglês, mammalian lethal with SEC13 protein 8), também conhecida como GßL e dois reguladores negativos PRAS40 e DEPTOR $(89,90)$. 0 segundo complexo, chamado de mTORC2 também é composto por mTOR, DEPTOR (do inglês, DEP domain-containing mTOR-interacting protein) e mLST8, além das subunidades Rictor (do inglês, rapamycin-insensitive companion of mTOR), mSin1 (do inglês mammalian stressactivated protein kinase (SAPK)-interacting protein 1), PROTOR, PRR5 (do inglês prolinerich protein 5) e Hsp70 (do inglês, Heat-shock protein 70) $(90,91)$. Embora a ativação de mTORC2 ainda não esteja muito clara, estudos mostram que a via PI3K- IKB kinase $\alpha$ (IKK $\alpha$ ) pode ativar mTORC2(92). Este, por sua vez é responsável pela fosforilação da Ser473 na AKT (91). Sabe-se que mTORC1 é ativado pela fosforilação de TSC1-TSC2, deixando de inibir Rheb e levando a uma regulação positiva de mTORC1. A molécula Raptor recruta a quinase S6 (p70S6K) e a proteína 4EBP1 (do inglês, Eukaryotic translation initiation factor $4 E$ (eIF4E)-binding protein 1)) (89). Dessa forma, mTORC1 fosforila e inativa o repressor de tradução de mRNA 4E-BP1 e fosforila e ativa a p70S6K que fosforila a proteína S6 ribossomal (S6) (93), fazendo deste complexo um regulador positivo da síntese de proteínas (Figura 4). 


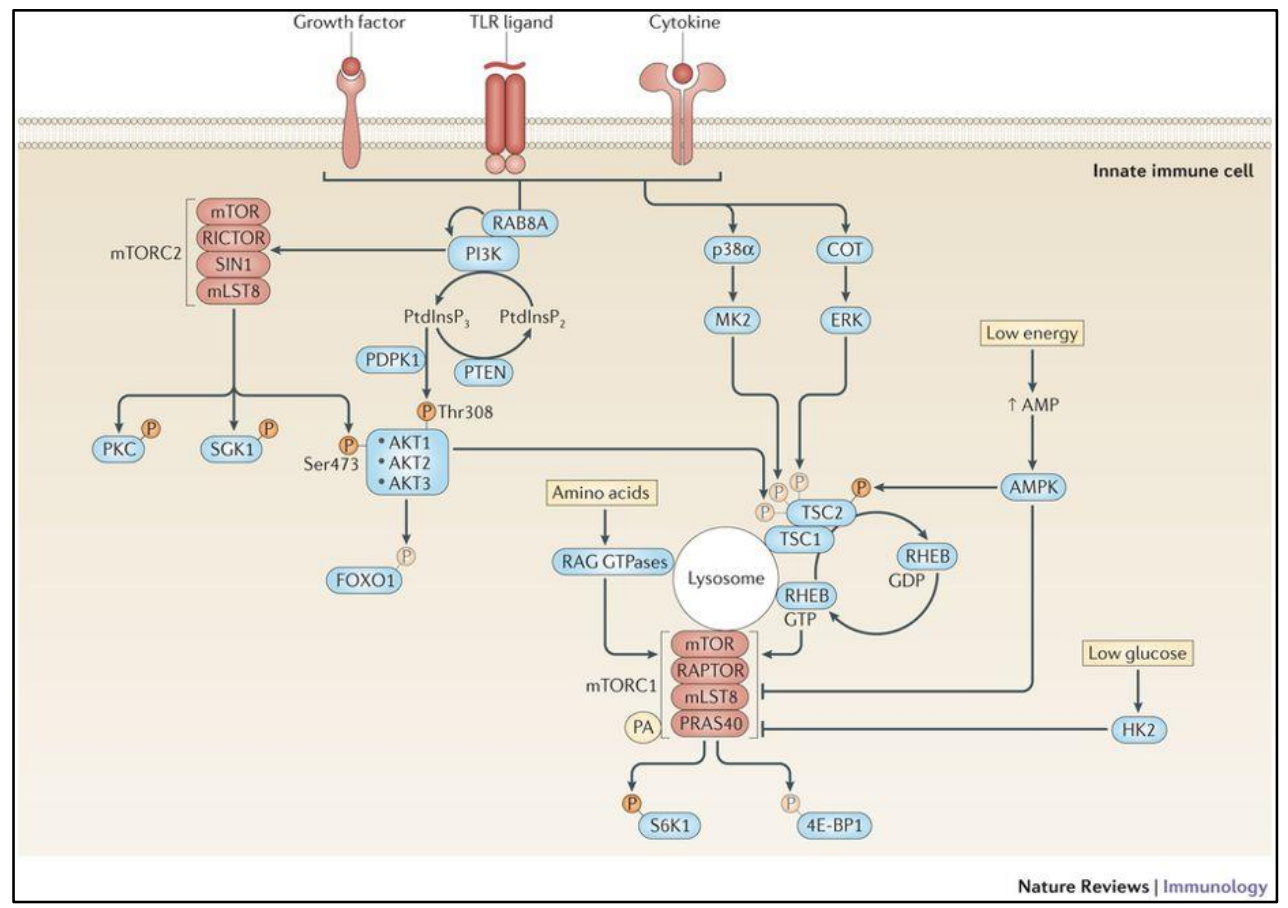

Figura 6. Ativação da via mTOR. A molécula mTOR existe em dois complexos proteicos distintos: mTORC1 (composto por mTOR, Raptor, MLST8), que é sensível à rapamicina e regulado por fatores de crescimento, ligantes de TLR e nutrientes e o mTORC2 (composto por mTOR, Rictor, Sin1, mLST8), indiretamente inibido pela rapamicina. Os substratos do mTORC1 ativado, melhores descritos até então, são 4E-BP1 e p70S6K, que estimulam síntese proteica e crescimento celular. mTORC2 é envolvido do rearranjo do citoesqueleto e sobrevivência celular. Adaptado de (94).

\subsubsection{Via mTOR em células da imunidade inata}

Nos últimos anos foi verificada a importância da via mTOR em células da imunidade inata, como neutrófilos, mastócitos, macrófagos e DCs mieloide e plasmocitóide (mDC e pDC) (94). A ativação das células da imunidade inata faz com que ocorram mudanças pronunciadas na morfologia dessas células, na capacidade migratória e na produção de citocinas, quimiocinas e mediadores lipídicos (95). Muitas dessas mudanças metabólicas são controladas pelos mTORC1 e 2, após a ativação celular (95). A via mTOR nas células da imunidade inata pode ser ativada por diferentes estímulos extracelulares, como fatores de crescimento, citocinas e ligantes de TLR (95). Os ligantes de TLR ativam mTORC1 e 2 em monócitos, macrófagos e DCs de humanos e de camundongos (96-100). A IL-4 ativa mTORC1 e 2 em macrófagos murinos e a IL-15 ativa mTORC1 em células NK em humanos e camundongos (101). A ativação da via mTOR nas células da imunidade inata se dá por vários intermediários encontrados em vias de sinalização acima dos complexos mTORC1 e 2 e culmina com a ativação de outros abaixo 
deles. mTORC1 ativado promove a síntese de proteínas em células da imunidade inata enquanto mTORC2 é relacionado a processos de reorganização do citoesqueleto e sobrevivência (95) (Figura 7).

No que diz respeito ao metabolismo, células da imunidade inata também controlam ativamente seus processos metabólicos para adaptar e otimizar suas funções efetoras conforme suas necessidades e nutrientes disponíveis no meio (102). A via mTOR é uma via central de regulação de diversos processos metabólicos $(103,104)$. A ativação de mTORC1 geralmente culmina com processos anabólicos que induzem a síntese de proteínas, ácidos nucleicos e lipídeos (105). Além disso, também é crucial para os processos de glicólise aeróbica e respiração mitocondrial, fornecendo energia para a célula montar uma resposta aos estímulos recebidos $(95,106,107)$. mTORC2 também está relacionado com o metabolismo glicolítico, com geração de lactato por meio da glicólise aeróbica (103). O lactato promove a reprogramação do metabolismo de macrófagos e DCs, pois diminui a expressão de IL-12 e aumenta a expressão de IL-10 (103).

A via mTOR controla a síntese de citocinas por células da imunidade inata (94). Porém, devido à complexidade da via, essa regulação é muito variável, assim como todo o controle metabólico feito por ela. Depende muito do ambiente em que se encontra a célula, se primária, derivada da medula óssea ou linhagem, se de humanos ou camundongos, entre outros fatores. Um exemplo é a produção de IL-12, como visto anteriormente. 0 aumento da atividade de mTORC1, pela inibição de TSC1, reduz a produção de IL-12 por DCs derivadas da medula óssea, mas aumenta a produção desta citocina por macrófagos derivados da medula, em camundongos (103) . A deleção de mTORC2 faz com que o fator de transcrição FOXO1 (do inglês, Forkhead box protein 01) deixe de ser inibido em DCs e macrófagos $(108,109)$. Sua consequente ativação leva ao aumento da expressão de genes inflamatórios e produção de IL-12 nessas células $(108,110)$.

A importância dos complexos da via mTOR no fenótipo das células da imunidade inata é verificada por inibição farmacológica dos mesmos ou deleção condicional. No caso dos macrófagos, a deleção condicional de TSC1 reduz a polarização para M2 em resposta à IL-4, tanto in vivo quanto in vitro (111). A inibição de mTORC1, por deleção de Raptor, diminui a resistência à insulina e inflamação por direcionar a polarização dos macrófagos para o perfil M2 (112). Já a deleção de Rictor, levando à inibição de mTORC2, aumenta à susceptibilidade ao choque induzido por LPS, devido à polarização dos macrófagos para 
o perfil M1 (113). Em mastócitos foi verificado que a ativação de mTORC1 é necessária para a sobrevivência e expressão de IL-8 e TNF após estimulação do receptor FcعRI (114, 115). O mTORC2 contribui para a quimiotaxia mediada pela prostaglandina $\mathrm{E}_{2}\left(\mathrm{PGE}_{2}\right)$, expressão de CCL2 e produção de ROS nessas células (116). Em células NK foi verificado que a IL-15 ativa mTORC1 que, por sua vez, é importante para a proliferação e citotoxicidade dessas células $(101,117,118)$. O tratamento com RAPA bloqueia a proliferação e expressão de IFN $\gamma$ e granzima B nas células NK, afetando a capacidade microbicida destas células e aumentando a carga viral de citomegalovírus nos camundongos tratados $(101,118)$.

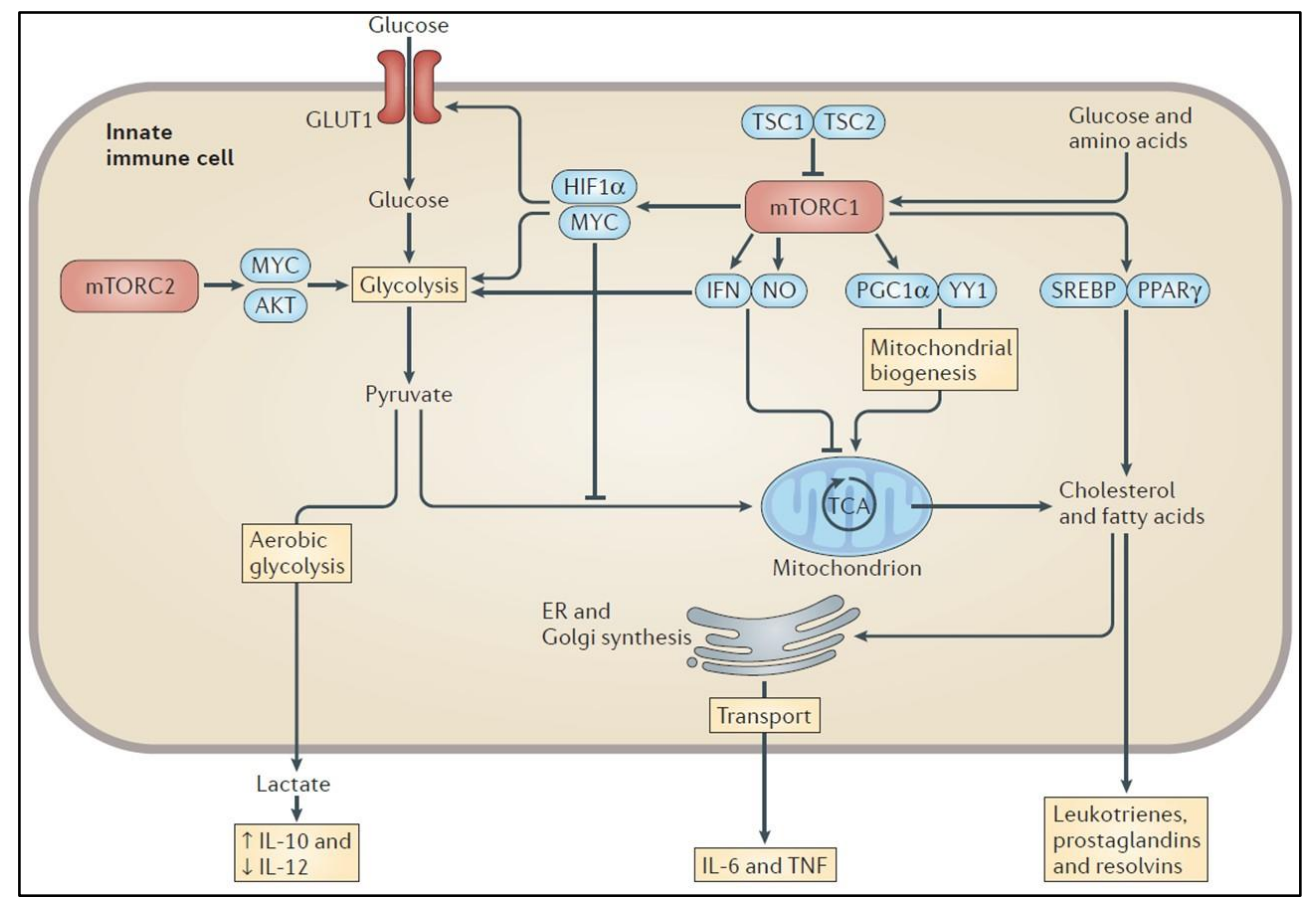

Figura 7. Importância dos complexos da via mTOR no metabolismo das células da imunidade inata. As células da imunidade inata têm um metabolismo diferente dos linfócitos, geralmente mais glicolítico, enquanto os linfócitos fazem mais fosforilação oxidativa. Os complexos da via mTOR estão envolvidos no metabolismos dessas células e ativam moléculas chave, levando à produção de citocinas e mediadores lipídicos (95).

\subsubsection{Via mTOR nos neutrófilos}

Inicialmente vistas como vias diferentes, hoje sabemos que PI3K e mTOR se comunicam via AKT (119). O papel dessas vias tem sido evidenciado nas funções dos neutrófilos. Estudos mostram que a via da PI3K regula a fagocitose nessas células, principalmente durante o engolfamento e internalização de partículas grandes (120). Da mesma forma, neutrófilos que não possuem PI3K $\gamma$ demonstram defeitos no burst 
oxidativo e na migração, quando estimulados com $\operatorname{fMLP}(121,122)$. Além disso, estudos com neutrófilos deletados de AKT2 mostram que essa quinase é importante para a quimiotaxia, produção de superóxido, degranulação e migração celular após estímulo com fMLP, C5a ou PMA (123).

Embora a ligação entre essas vias seja extensa, pouco são os estudos envolvendo a via mTOR e os neutrófilos. Em relação ao mTORC1, foi verificado que ligantes de TLR e os fatores de crescimento GM-CSF (do inglês, granulocyte-macrophage colony-stimulating factor)e FMS-related tyrosine kinase 3 ligand (FlT3L) induzem a ativação desse complexo em neutrófilos $(94,124)$ e DCs $(94,96,125,126)$. Além disso, visto que o papel do mTORC1 se baseia no controle da síntese de proteínas, ele pode atuar nos neutrófilos induzindo a tradução de mRNA pré-existentes (127). Desta forma, foi visto que a ativação de mTORC1 induz a síntese da ciclo-oxigenase 2 (COX2), levando ao aumento de PGE2 e atuando de maneira pro-inflamatória nessas células (128). Além disso, mTORC1 está envolvido na expressão de IL-6 sem a necessidade de uma síntese de novo dessa citocina (127).. Desta forma, inibir mTORC1 pode levar a uma resposta menos inflamatória por parte dos neutrófilos (95).

Outra ação importante da via mTOR nos neutrófilos é em relação à formação das NETs. Porém, os estudos em questão fazem uso da RAPA e não distinguem os complexos da via mTOR envolvidos $(83,129)$. Sendo assim, o mecanismo molecular de ação da via mTOR nas NETs ainda precisa ser melhor estudado. Em 2012, McInturff et al. observaram que a via mTOR regula a formação das NETs por induzir o fator de transcrição HIF-1 $\alpha$, usando como estímulo LPS. Assim, inibindo a via mTOR por meio da RAPA, eles verificaram uma diminuição da expressão de HIF-1 $\alpha$, associando, então, a inibição das NETs ao fator de transcrição (83). Diferentemente do trabalho de McInturff et al., em 2013, um outro grupo de pesquisa sugeriu que a inibição da via mTOR contribui para a produção das NETs (129). Itakura et al. sugerem que a autofagia, juntamente com a produção de ROS, são importantes para a formação das NETs após estímulo com fMLP e que a via mTOR regula negativamente a autofagia nos neutrófilos (129). Tendo em vista a complexidade da regulação da via mTOR, principalmente em células do sistema imune, a disparidade entre os trabalhos citados pode ser devida aos estímulos usados.

Embora com ativação e atuação ainda pouco conhecidas, estudos mais recentes têm demonstrado que o mTORC2 atua na regulação do rearranjo do citoesqueleto nos neutrófilos por agir na F-actina e Miosina II $(18,130)$. Esses estudos fizeram uso de knock- 
down de Rictor em linhagens celulares e observaram que a migração dessas células está prejudicada na ausência de mTORC2 $(18,130)$.

Sendo assim, embora alguns trabalhos tenham demonstrado a participação da via PI3K e, mesmo, mTOR em neutrófilos $(95,120)$, pouco se sabe sobre a ação dos complexos mTORC1 e mTORC2 nestas células e, principalmente, a influência dos mesmos na resposta imune frente a um patógeno, como no caso da sepse. Portanto, o estudo da via mTOR em um contexto inflamatório/infeccioso, como a sepse, pode contribuir para elucidar possíveis mecanismos de ação dessa via, sendo importante para futuras estratégias terapêuticas na sepse.

\subsection{Sepse: definição e fisiopatologia}

A sepse é uma síndrome causada por uma resposta inflamatória sistêmica descontrolada induzida por uma infecção (131). Em 1991 foi introduzido o termo SIRS (systemic inflammatory response syndrome) após uma conferência entre o American College of Chest Physicians (ACCP) e a Society of Critical Care Medicine (SCCM), para universalizar a definição de sepse. A SIRS é definida como uma combinação de sinais clínicos sem a existência de infecção $(132,133)$. Portanto, o diagnóstico de sepse só era feito quando havia um agente infeccioso associado ao quadro de SIRS. Desta forma, a sepse foi dividida em sepse severa e choque séptico, sendo que a primeira é definida como sepse associada à disfunção de um ou mais órgãos e o choque séptico é definido como sepse severa associada à necessidade de medicamentos vasoativos (134). Como esses conceitos não eram revisados desde 2001, ocorreu, em 2016, uma força-tarefa que mobilizou a Society of Critical Care Medicine (SCCM) e a European Society of Intensive Care Medicine (ESICM) (131). Com isso, foi proposta uma nova definição de sepse, chamada de Sepse-3. A nova proposta evidencia a resposta inflamatória descontrolada em um quadro de sepse, que leva à disfunção de órgãos e ao risco de morte (131). Nesse novo consenso, os critérios de SIRS para identificar um quadro de sepse foram abandonados, e o termo sepse severa foi eliminado. Atualmente, os critérios para identificação de um paciente com sepse provêm do SOFA (do inglês, Sequential Organ Failure Assessment) $(131,135)$. Os critérios do SOFA incluem: taxa respiratória, frequência cardíaca, coagulação, função hepática, função renal e se o paciente apresenta algum grau de coma (135). Em relação ao choque séptico, o novo consenso o define como um subconjunto da sepse. Quando se observa anormalidades circulatórias e metabólicas profundas no paciente que aumentam 
o risco de morte, ele é enquadrado no choque séptico (131). Embora as definições e critérios sejam para melhorar a identificação e tratamento dessa síndrome, sempre há limitações. A principal limitação levantada por especialistas na área é a baixa sensibilidade para identificação precoce de quadros de sepse, momento em que o tratamento é mais eficaz (136).

O sistema imune inato, que responde prontamente ao agente invasor, é crucial para dar início à imunofisiopatologia da sepse (137). A ativação das células da imunidade inata, principalmente os neutrófilos e macrófagos residentes, resulta em exacerbada liberação de citocinas, quimiocinas e outros mediadores inflamatórios. Dentre as principais citocinas relacionadas à sepse, se destacam, TNF- $\alpha$, IL-1 e IL-6, produzidas por neutrófilos e macrófagos (138-141). 0 papel destas citocinas na sepse foi demonstrado em inúmeros trabalhos, incluindo humanos e modelos animais. TNF- $\alpha$ e IL-1 $\beta$ agem em diferentes tipos celulares, como macrófagos, células endoteliais e neutrófilos, promovendo a ativação dessas células (137). Desta forma, estas citocinas amplificam a cascata inflamatória, fazendo com que os macrófagos secretem IL-6, IL-8 e MIF, mediadores lipídicos e ROS e RNS, também secretadas pelos neutrófilos, levando a disfunção dos órgãos na sepse (142, 143). Além disso, TNF- $\alpha$ e IL-1 $\beta$ pertencem ao grupo de citocinas pirogênicas, sendo importantes mediadores no desenvolvimento da febre (144). Uma das principais funções da IL-6 também é o controle da temperatura, porém de forma dependente de TNF- $\alpha$ e IL1. A IL-6 induz a produção de prostaglandinas no sistema nervoso central, o que gera a febre (145). A IL-6 também é apontada como marcador de severidade da doença, sendo que o bloqueio com anticorpo específico diminui a mortalidade em camundongos (146). Além da IL-6, outros fatores podem indicar uma sepse mais severa, como a temperatura corporal e a migração de células para o local da infecção.

O aumento da temperatura corporal é a manifestação mais comum na sepse e, como em outras infecções, acredita-se que a febre seja um fator determinante para o sistema imune eliminar o agente infeccioso (147). No entanto, em um quadro de sepse mais grave a febre dá espaço à hipotermia, de forma que esta é usada como um indicativo de severidade da sepse (148).

\subsubsection{Importância dos neutrófilos na sepse}

Os neutrófilos são as principais células envolvidas na sepse $[9,10]$. Por meio das suas funções efetoras, como a fagocitose, liberação de oxidantes e das NETs, os neutrófilos 
são importantes para conter os patógenos envolvidos nessa síndrome $[9,11,12]$. No entanto, num quadro de sepse grave, em que a quantidade de microorganismos é exacerbada, o recrutamento de neutrófilos para o local da infecção é prejudicado, fazendo com que estas células migrem para órgãos distantes (149). Tavares-Murta e colaboradores demonstraram, em 2002, que neutrófilos de pacientes com sepse possuem uma supressão da quimiotaxia em resposta ao quimioatraente fMLP e ao leucotrieno $\mathrm{B}_{4}$ (LTB4). Além disso, neste trabalho, os pesquisadores fizeram uma associação da supressão da quimiotaxia dos neutrófilos com a severidade da doença, sugerindo que a disfunção na migração destas células pode ser um marcador de pior prognóstico da doença (149).

Dentro do contexto da sepse, em que há altos níveis de quimiocinas e citocinas circulantes, o defeito na migração dos neutrófilos não é decorrente de uma carência destes mediadores. Pelo contrário, embora os mecanismos envolvidos na falha de migração dos neutrófilos não estejam completamente esclarecidos, a excessiva produção de citocinas, quimiocinas, proteínas de fase aguda, além do aumento da atividade da iNOS, HO (hemeoxigenase)-1 e ativação sistêmica de TLRs (toll-like receptors) durante a sepse, contribuem para o defeito na migração dos neutrófilos para o sítio de infecção por inibir proteínas importante para a quimiotaxia, como o CXCR2, por exemplo (150-154).

A lesão tecidual causada pelos neutrófilos, devido à liberação desregulada de ROS e RNS e, também, das NETs é uma das causas que leva à disfunção dos órgãos na sepse (155-157). A fagocitose, que leva à produção de ROS pelos neutrófilos, e a liberação das NETs são etapas cruciais para conter e eliminar o patógeno $(155,156,158)$. A característica central do processo inflamatório durante a sepse aguda é o acúmulo de neutrófilos ativados na microcirculação de órgãos altamente vascularizados, como fígado, pulmões e rins (159), levando a um dano tecidual e, posteriormente, disfunção dos órgãos mediados pelo sistema imune $(160,161)$. Recentemente, o papel das NETs na sepse tem se destacado e muitos trabalhos demonstram a sua importância, principalmente, no clearance de bactérias (156). No entanto, os componentes microbicidas presentes nas NETs contribuem para o dano tecidual (157), não apenas na sepse, mas em outras doenças como o lúpus eritematoso sistêmico (162) e aterosclerose (163). Sendo assim, os efeitos benéficos da liberação de NETs durante a sepse são controversos. Certamente, as NETs tem um papel crucial na contenção dos microrganismos durante a sepse, sendo que quando não há a formação dessas estruturas, as bactérias conseguem atingir e colonizar 
órgãos distantes mais rapidamente (158). No entanto, trabalhos mostram que as histonas, componente central das NETs, são os principais mediadores da disfunção endotelial, causando a morte dos pacientes com sepse $(157,164)$. Diante deste cenário, é evidente que o efetivo balanço entre a liberação das NETs e o seu clearance é a melhor estratégia diante de um quadro de sepse. Esse balanço não é visto apenas em relação às NETs. As funções efetoras dos neutrófilos em geral, incluindo a degranulação e a produção de ROS, levam ao dano tecidual se não forem controladas. Sendo assim, o grande desafio diante da sepse é atingir esse equilíbrio entre a resposta imune e a eliminação do patógeno. 


\section{REFERÊNCIAS*}

1. de Visser KE, Eichten A, Coussens LM. Paradoxical roles of the immune system during cancer development. Nature reviews Cancer. 2006;6(1):24-37.

2. Degli-Esposti MA, Smyth MJ. Close encounters of different kinds: dendritic cells and NK cells take centre stage. Nature reviews Immunology. 2005;5(2):112-24.

3. Kumar V, Sharma A. Neutrophils: Cinderella of innate immune system. International immunopharmacology. 2010;10(11):1325-34.

4. Banchereau J, Steinman RM. Dendritic cells and the control of immunity. Nature. 1998;392(6673):245-52.

5. Johansson M, Denardo DG, Coussens LM. Polarized immune responses differentially regulate cancer development. Immunological reviews. 2008;222:145-54.

6. Mayadas TN, Cullere X, Lowell CA. The multifaceted functions of neutrophils. Annu Rev Pathol. 2014;9:181-218.

7. Ribeiro C BM. Insect haemocytes: what type of cell is that? Journal Insect Physiology. 2006;May;52(5)(May;52(5)):417-29.

8. SW. E. The development and structure of mature neutrophils. Biochemistry and Physiology of the Neutrophil. 2005:33-76.

9. Kay AB. Paul Ehrlich and the Early History of Granulocytes. Microbiol Spectr. 2016;4(4).

10. Nathan C. Neutrophils and immunity: challenges and opportunities. Nature reviews Immunology. 2006;6(3):173-82.

11. Mantovani A, Cassatella MA, Costantini C, Jaillon S. Neutrophils in the activation and regulation of innate and adaptive immunity. Nature reviews Immunology. 2011;11(8):519-31.

12. Kolaczkowska E, Kubes P. Neutrophil recruitment and function in health and inflammation. Nature reviews Immunology. 2013;13(3):159-75.

13. Brinkmann V, Reichard U, Goosmann C, Fauler B, Uhlemann Y, Weiss DS, et al. Neutrophil extracellular traps kill bacteria. Science. 2004;303(5663):1532-5.

14. Rosales C, Demaurex N, Lowell CA, Uribe-Querol E. Neutrophils: Their Role in Innate and Adaptive Immunity. J Immunol Res. 2016;2016:1469780.

15. Hind LE, Vincent WJ, Huttenlocher A. Leading from the Back: The Role of the Uropod in Neutrophil Polarization and Migration. Dev Cell. 2016;38(2):161-9.

16. Petri B, Sanz MJ. Neutrophil chemotaxis. Cell Tissue Res. 2018;371(3):425-36.

17. Liu L, Gritz D, Parent CA. PKC $B I I$ acts downstream of chemoattractant receptors and mTORC2 to regulate cAMP production and myosin II activity in neutrophils. Mol Biol Cell. 2014;25(9):1446-57.

18. Liu L, Das S, Losert W, Parent CA. mTORC2 regulates neutrophil chemotaxis in a CAMP- and RhoA-dependent fashion. Developmental cell. 2010;19(6):845-57.

19. Bainton DF, Farquhar MG. Origin of granules in polymorphonuclear leukocytes. Two types derived from opposite faces of the Golgi complex in developing granulocytes. J Cell Biol. 1966;28(2):277-301.

20. Faurschou $M$, Borregaard N. Neutrophil granules and secretory vesicles in inflammation. Microbes Infect. 2003;5(14):1317-27.

21. Lacy P. Mechanisms of degranulation in neutrophils. Allergy Asthma Clin Immunol. 2006;2(3):98-108.

22. Gomperts BD. GE: a GTP-binding protein mediating exocytosis. Annu Rev Physiol. 1990;52:591606.

23. Barlic J, Andrews JD, Kelvin AA, Bosinger SE, DeVries ME, Xu L, et al. Regulation of tyrosine kinase activation and granule release through beta-arrestin by CXCRI. Nat Immunol. 2000;1(3):227-33. 24. Abdel-Latif D, Steward M, Macdonald DL, Francis GA, Dinauer MC, Lacy P. Rac2 is critical for neutrophil primary granule exocytosis. Blood. 2004;104(3):832-9. 
25. Fensome A, Cunningham E, Prosser S, Tan SK, Swigart P, Thomas G, et al. ARF and PITP restore GTP gamma S-stimulated protein secretion from cytosol-depleted HL60 cells by promoting PIP2 synthesis. Curr Biol. 1996;6(6):730-8.

26. Burgoyne RD, Morgan A. Secretory granule exocytosis. Physiol Rev. 2003;83(2):581-632.

27. Sengel $\varnothing \mathrm{V} \mathrm{H}$, Kjeldsen L, Borregaard N. Control of exocytosis in early neutrophil activation. J Immunol. 1993;150(4):1535-43.

28. Scapini P, Calzetti F, Cassatella MA. On the detection of neutrophil-derived vascular endothelial growth factor (VEGF). J Immunol Methods. 1999;232(1-2):121-9.

29. Tecchio C, Micheletti A, Cassatella MA. Neutrophil-derived cytokines: facts beyond expression. Front Immunol. 2014;5:508.

30. Cassatella MA. Neutrophil-derived proteins: selling cytokines by the pound. Adv Immunol. 1999;73:369-509.

31. Jaillon S, Galdiero MR, Del Prete D, Cassatella MA, Garlanda C, Mantovani A. Neutrophils in innate and adaptive immunity. Semin Immunopathol. 2013;35(4):377-94.

32. Lee WL, Harrison RE, Grinstein S. Phagocytosis by neutrophils. Microbes and infection. 2003;5(14):1299-306.

33. Beachy JC, Weisman LE. Acute asphyxia affects neutrophil number and function in the rat. Crit Care Med. 1993;21(12):1929-34.

34. Baldridge CW, Gerard, R. W. . The extra respiration of phagocytosis. Am J Physiol. 1933;103:235-6.

35. Babior BM. NADPH oxidase: an update. Blood. 1999;93(5):1464-76.

36. Babior BM, Curnutte JT, McMurrich BJ. The particulate superoxide-forming system from human neutrophils. Properties of the system and further evidence supporting its participation in the respiratory burst. The Journal of clinical investigation. 1976;58(4):989-96.

37. Quinn MT, Ammons MC, Deleo FR. The expanding role of NADPH oxidases in health and disease: no longer just agents of death and destruction. Clin Sci (Lond). 2006;111(1):1-20.

38. Kavanagh K, Reeves EP. Exploiting the potential of insects for in vivo pathogenicity testing of microbial pathogens. FEMS Microbiol Rev. 2004;28(1):101-12.

39. DeLeo FR, Allen LA, Apicella M, Nauseef WM. NADPH oxidase activation and assembly during phagocytosis. J Immunol. 1999;163(12):6732-40.

40. Bylund J, Brown KL, Movitz C, Dahlgren C, Karlsson A. Intracellular generation of superoxide by the phagocyte NADPH oxidase: how, where, and what for? Free radical biology \& medicine. 2010;49(12):1834-45.

41. Manda-Handzlik A, Demkow U. Neutrophils: The Role of Oxidative and Nitrosative Stress in Health and Disease. Adv Exp Med Biol. 2015;857:51-60.

42. Saini R, Singh S. Inducible nitric oxide synthase: An asset to neutrophils. J Leukoc Biol. 2019;105(1):49-61.

43. Berka V, Wang LH, Tsai AL. Oxygen-induced radical intermediates in the nNOS oxygenase domain regulated by L-arginine, tetrahydrobiopterin, and thiol. Biochemistry. 2008;47(1):405-20.

44. Stuehr DJ, Marletta MA. Mammalian nitrate biosynthesis: mouse macrophages produce nitrite and nitrate in response to Escherichia coli lipopolysaccharide. Proceedings of the National Academy of Sciences of the United States of America. 1985;82(22):7738-42.

45. Bogdan C. Nitric oxide and the immune response. Nature immunology. 2001;2(10):907-16.

46. Beckman JS, Koppenol WH. Nitric oxide, superoxide, and peroxynitrite: the good, the bad, and ugly. The American journal of physiology. 1996;271(5 Pt 1):C1424-37.

47. Brinkmann V, Zychlinsky A. Neutrophil extracellular traps: is immunity the second function of chromatin? The Journal of cell biology. 2012;198(5):773-83.

48. Takei H, Araki A, Watanabe H, Ichinose A, Sendo F. Rapid killing of human neutrophils by the potent activator phorbol 12-myristate 13-acetate (PMA) accompanied by changes different from typical apoptosis or necrosis. Journal of leukocyte biology. 1996;59(2):229-40. 
49. Steinberg BE, Grinstein S. Unconventional roles of the NADPH oxidase: signaling, ion homeostasis, and cell death. Science's STKE : signal transduction knowledge environment. 2007;2007(379):pe11.

50. Douda DN, Yip L, Khan MA, Grasemann H, Palaniyar N. Akt is essential to induce NADPHdependent NETosis and to switch the neutrophil death to apoptosis. Blood. 2014;123(4):597-600.

51. Hakkim A, Fuchs TA, Martinez NE, Hess S, Prinz H, Zychlinsky A, et al. Activation of the RafMEK-ERK pathway is required for neutrophil extracellular trap formation. Nature chemical biology. 2011;7(2):75-7.

52. Douda DN, Khan MA, Grasemann H, Palaniyar N. SK3 channel and mitochondrial ROS mediate NADPH oxidase-independent NETosis induced by calcium influx. Proc Natl Acad Sci U S A. 2015;112(9):2817-22.

53. Yousefi S, Mihalache C, Kozlowski E, Schmid I, Simon HU. Viable neutrophils release mitochondrial DNA to form neutrophil extracellular traps. Cell death and differentiation. 2009;16(11):1438-44.

54. Metzler KD, Goosmann C, Lubojemska A, Zychlinsky A, Papayannopoulos V. A myeloperoxidase-containing complex regulates neutrophil elastase release and actin dynamics during NETosis. Cell Rep. 2014;8(3):883-96.

55. Papayannopoulos V, Metzler KD, Hakkim A, Zychlinsky A. Neutrophil elastase and myeloperoxidase regulate the formation of neutrophil extracellular traps. J Cell Biol. 2010;191(3):67791.

56. Stoiber W, Obermayer A, Steinbacher P, Krautgartner WD. The Role of Reactive Oxygen Species (ROS) in the Formation of Extracellular Traps (ETs) in Humans. Biomolecules. 2015;5(2):702-23.

57. Alwarawrah Y, Kiernan K, Maclver NJ. Changes in Nutritional Status Impact Immune Cell Metabolism and Function. Front Immunol. 2018;9:1055.

58. Pearce EL, Pearce EJ. Metabolic pathways in immune cell activation and quiescence. Immunity. 2013;38(4):633-43.

59. Seatter MJ, Gould GW. The mammalian facilitative glucose transporter (GLUT) family. Pharm Biotechnol. 1999;12:201-28.

60. Macintyre AN, Gerriets VA, Nichols AG, Michalek RD, Rudolph MC, Deoliveira D, et al. The glucose transporter Glut1 is selectively essential for CD4 T cell activation and effector function. Cell Metab. 2014;20(1):61-72.

61. Schuster DP, Brody SL, Zhou Z, Bernstein M, Arch R, Link D, et al. Regulation of lipopolysaccharide-induced increases in neutrophil glucose uptake. Am J Physiol Lung Cell Mol Physiol. 2007;292(4):L845-51.

62. Fukuzumi M, Shinomiya $H$, Shimizu $Y$, Ohishi K, Utsumi S. Endotoxin-induced enhancement of glucose influx into murine peritoneal macrophages via GLUT1. Infect Immun. 1996;64(1):108-12.

63. Mookerjee SA, Goncalves RLS, Gerencser AA, Nicholls DG, Brand MD. The contributions of respiration and glycolysis to extracellular acid production. Biochim Biophys Acta. 2015;1847(2):17181.

64. Gladden LB. Lactate metabolism: a new paradigm for the third millennium. J Physiol. 2004;558(Pt 1):5-30.

65. O W. Versuche an Überlebendem

Carcinomgewebe. In: S. M, editor. Klin Wochenschr. 1923. p. 776-7.

66. Chen LB. Mitochondrial membrane potential in living cells. Annu Rev Cell Biol. 1988;4:155-81.

67. Schultz BE, Chan SI. Structures and proton-pumping strategies of mitochondrial respiratory enzymes. Annu Rev Biophys Biomol Struct. 2001;30:23-65.

68. Nath S. The molecular mechanism of ATP synthesis by F1F0-ATP synthase: a scrutiny of the major possibilities. Adv Biochem Eng Biotechnol. 2002;74:65-98.

69. Hamanaka RB, Chandel NS. Mitochondrial reactive oxygen species regulate cellular signaling and dictate biological outcomes. Trends Biochem Sci. 2010;35(9):505-13. 
70. Sena LA, Chandel NS. Physiological roles of mitochondrial reactive oxygen species. Mol Cell. 2012;48(2):158-67.

71. VALENTINE WN, BECK WS. Biochemical studies on leucocytes. I. Phosphatase activity in health, leucocytosis, and myelocytic leucemia. J Lab Clin Med. 1951;38(1):39-55.

72. SBARRA AJ, KARNOVSKY ML. The biochemical basis of phagocytosis. I. Metabolic changes during the ingestion of particles by polymorphonuclear leukocytes. J Biol Chem. 1959;234(6):1355-62. 73. Fossati G, Moulding DA, Spiller DG, Moots RJ, White MR, Edwards SW. The mitochondrial network of human neutrophils: role in chemotaxis, phagocytosis, respiratory burst activation, and commitment to apoptosis. J Immunol. 2003;170(4):1964-72.

74. Borregaard N, Herlin T. Energy metabolism of human neutrophils during phagocytosis. J Clin Invest. 1982;70(3):550-7.

75. Kramer PA, Ravi S, Chacko B, Johnson MS, Darley-Usmar VM. A review of the mitochondrial and glycolytic metabolism in human platelets and leukocytes: implications for their use as bioenergetic biomarkers. Redox Biol. 2014;2:206-10.

76. Riffelmacher T, Clarke A, Richter FC, Stranks A, Pandey S, Danielli S, et al. AutophagyDependent Generation of Free Fatty Acids Is Critical for Normal Neutrophil Differentiation. Immunity. 2017;47(3):466-80.e5.

77. Griffiths HR, Gao D, Pararasa C. Redox regulation in metabolic programming and inflammation. Redox Biol. 2017;12:50-7.

78. Stanton RC. Glucose-6-phosphate dehydrogenase, NADPH, and cell survival. IUBMB Life. 2012;64(5):362-9.

79. Valko M, Leibfritz D, Moncol J, Cronin MT, Mazur M, Telser J. Free radicals and antioxidants in normal physiological functions and human disease. Int J Biochem Cell Biol. 2007;39(1):44-84.

80. Ganeshan K, Chawla A. Metabolic regulation of immune responses. Annu Rev Immunol. 2014;32:609-34.

81. Cramer T, Yamanishi Y, Clausen BE, Förster I, Pawlinski R, Mackman N, et al. HIF-1alpha is essential for myeloid cell-mediated inflammation. Cell. 2003;112(5):645-57.

82. Peyssonnaux C, Datta V, Cramer T, Doedens A, Theodorakis EA, Gallo RL, et al. HIF-1alpha expression regulates the bactericidal capacity of phagocytes. J Clin Invest. 2005;115(7):1806-15.

83. McInturff AM, Cody MJ, Elliott EA, Glenn JW, Rowley JW, Rondina MT, et al. Mammalian target of rapamycin regulates neutrophil extracellular trap formation via induction of hypoxia-inducible factor 1 alpha. Blood. 2012;120(15):3118-25.

84. Wullschleger $\mathrm{S}$, Loewith $\mathrm{R}$, Hall MN. TOR signaling in growth and metabolism. Cell. 2006;124(3):471-84.

85. Weichhart T, Saemann MD. The multiple facets of mTOR in immunity. Trends in immunology. 2009;30(5):218-26.

86. Pearce $L R$, Komander D, Alessi DR. The nuts and bolts of AGC protein kinases. Nat Rev Mol Cell Biol. 2010;11(1):9-22.

87. Manning BD, Toker A. AKT/PKB Signaling: Navigating the Network. Cell. 2017;169(3):381-405.

88. Huang J, Manning BD. A complex interplay between Akt, TSC2 and the two mTOR complexes. Biochemical Society transactions. 2009;37(Pt 1):217-22.

89. Kim DH, Sabatini DM. Raptor and mTOR: subunits of a nutrient-sensitive complex. Current topics in microbiology and immunology. 2004;279:259-70.

90. Zhou H, Huang $\mathrm{S}$. The complexes of mammalian target of rapamycin. Current protein \& peptide science. 2010;11(6):409-24.

91. Sarbassov DD, Ali SM, Kim DH, Guertin DA, Latek RR, Erdjument-Bromage H, et al. Rictor, a novel binding partner of $\mathrm{mTOR}$, defines a rapamycin-insensitive and raptor-independent pathway that regulates the cytoskeleton. Current biology : CB. 2004;14(14):1296-302.

92. Dan HC, Antonia RJ, Baldwin AS. PI3K/Akt promotes feedforward mTORC2 activation through IKKa. Oncotarget. 2016;7(16):21064-75.

93. Hay N, Sonenberg N. Upstream and downstream of mTOR. Genes \& development. 2004;18(16):1926-45. 
94. Weichhart $\mathrm{T}$, Hengstschläger $\mathrm{M}$, Linke $\mathrm{M}$. Regulation of innate immune cell function by mTOR. Nat Rev Immunol. 2015;15(10):599-614.

95. Weichhart T, Hengstschlager M, Linke M. Regulation of innate immune cell function by mTOR. Nature reviews Immunology. 2015;15(10):599-614.

96. Haidinger M, Poglitsch M, Geyeregger R, Kasturi S, Zeyda M, Zlabinger GJ, et al. A versatile role of mammalian target of rapamycin in human dendritic cell function and differentiation. J Immunol. 2010;185(7):3919-31.

97. Fukao $\mathrm{T}$, Tanabe $\mathrm{M}$, Terauchi $\mathrm{Y}$, Ota $\mathrm{T}$, Matsuda $\mathrm{S}$, Asano $\mathrm{T}$, et al. PI3K-mediated negative feedback regulation of IL-12 production in DCs. Nature immunology. 2002;3(9):875-81.

98. Ohtani M, Nagai S, Kondo S, Mizuno S, Nakamura K, Tanabe M, et al. Mammalian target of rapamycin and glycogen synthase kinase 3 differentially regulate lipopolysaccharide-induced interleukin-12 production in dendritic cells. Blood. 2008;112(3):635-43.

99. Weichhart T, Costantino G, Poglitsch M, Rosner M, Zeyda M, Stuhlmeier KM, et al. The TSCmTOR signaling pathway regulates the innate inflammatory response. Immunity. 2008;29(4):565-77.

100. Schmitz F, Heit A, Dreher S, Eisenacher K, Mages J, Haas T, et al. Mammalian target of rapamycin (mTOR) orchestrates the defense program of innate immune cells. European journal of immunology. 2008;38(11):2981-92.

101. Marcais A, Cherfils-Vicini J, Viant C, Degouve S, Viel S, Fenis A, et al. The metabolic checkpoint kinase mTOR is essential for IL-15 signaling during the development and activation of NK cells. Nature immunology. 2014;15(8):749-57.

102. O'Neill LA, Hardie DG. Metabolism of inflammation limited by AMPK and pseudo-starvation. Nature. 2013;493(7432):346-55.

103. Masui K, Cavenee WK, Mischel PS. mTORC2 in the center of cancer metabolic reprogramming. Trends in endocrinology and metabolism: TEM. 2014;25(7):364-73.

104. Laplante M, Sabatini DM. mTOR signaling in growth control and disease. Cell. 2012;149(2):27493.

105. Inoki K, Kim J, Guan KL. AMPK and mTOR in cellular energy homeostasis and drug targets. Annu Rev Pharmacol Toxicol. 2012;52:381-400.

106. Roberts DJ, Tan-Sah VP, Ding EY, Smith JM, Miyamoto S. Hexokinase-II positively regulates glucose starvation-induced autophagy through TORC1 inhibition. Molecular cell. 2014;53(4):521-33.

107. Haller JF, Krawczyk SA, Gostilovitch L, Corkey BE, Zoeller RA. Glucose-6-phosphate isomerase deficiency results in mTOR activation, failed translocation of lipin 1alpha to the nucleus and hypersensitivity to glucose: Implications for the inherited glycolytic disease. Biochimica et biophysica acta. 2011;1812(11):1393-402.

108. Brown J, Wang H, Suttles J, Graves DT, Martin M. Mammalian target of rapamycin complex 2 (mTORC2) negatively regulates Toll-like receptor 4-mediated inflammatory response via FoxO1. The Journal of biological chemistry. 2011;286(52):44295-305.

109. Fan W, Morinaga H, Kim JJ, Bae E, Spann NJ, Heinz S, et al. FoxO1 regulates TIr4 inflammatory pathway signalling in macrophages. EMBO J. 2010;29(24):4223-36.

110. Raich-Regue D, Rosborough BR, Watson AR, McGeachy MJ, Turnquist HR, Thomson AW. mTORC2 Deficiency in Myeloid Dendritic Cells Enhances Their Allogeneic Th1 and Th17 Stimulatory Ability after TLR4 Ligation In Vitro and In Vivo. J Immunol. 2015;194(10):4767-76.

111. Zhu L, Yang T, Li L, Sun L, Hou Y, Hu X, et al. TSC1 controls macrophage polarization to prevent inflammatory disease. Nature communications. 2014;5:4696.

112. Jiang H, Westerterp M, Wang C, Zhu Y, Ai D. Macrophage mTORC1 disruption reduces inflammation and insulin resistance in obese mice. Diabetologia. 2014;57(11):2393-404.

113. Festuccia WT, Pouliot P, Bakan I, Sabatini DM, Laplante M. Myeloid-specific Rictor deletion induces M1 macrophage polarization and potentiates in vivo pro-inflammatory response to lipopolysaccharide. PloS one. 2014;9(4):e95432.

114. Kim MS, Kuehn HS, Metcalfe DD, Gilfillan AM. Activation and function of the mTORC1 pathway in mast cells. J Immunol. 2008;180(7):4586-95. 
115. Shin J, Pan H, Zhong XP. Regulation of mast cell survival and function by tuberous sclerosis complex 1. Blood. 2012;119(14):3306-14.

116. Kuehn HS, Jung MY, Beaven MA, Metcalfe DD, Gilfillan AM. Prostaglandin E2 activates and utilizes mTORC2 as a central signaling locus for the regulation of mast cell chemotaxis and mediator release. The Journal of biological chemistry. 2011;286(1):391-402.

117. Donnelly RP, Loftus RM, Keating SE, Liou KT, Biron CA, Gardiner CM, et al. mTORC1-dependent metabolic reprogramming is a prerequisite for NK cell effector function. J Immunol. 2014;193(9):447784.

118. Nandagopal N, Ali AK, Komal AK, Lee SH. The Critical Role of IL-15-PI3K-mTOR Pathway in Natural Killer Cell Effector Functions. Frontiers in immunology. 2014;5:187.

119. Weichhart T, Säemann MD. The PI3K/Akt/mTOR pathway in innate immune cells: emerging therapeutic applications. Ann Rheum Dis. 2008;67 Suppl 3:iii70-4.

120. Hannigan $\mathrm{MO}$, Huang $\mathrm{CK}, \mathrm{Wu} \mathrm{DQ}$. Roles of PI3K in neutrophil function. Current topics in microbiology and immunology. 2004;282:165-75.

121. Kodama T, Hazeki K, Hazeki O, Okada T, Ui M. Enhancement of chemotactic peptide-induced activation of phosphoinositide 3-kinase by granulocyte-macrophage colony-stimulating factor and its relation to the cytokine-mediated priming of neutrophil superoxide-anion production. The Biochemical journal. 1999;337 ( Pt 2):201-9.

122. Hirsch E, Katanaev VL, Garlanda C, Azzolino O, Pirola L, Silengo L, et al. Central role for G protein-coupled phosphoinositide 3-kinase gamma in inflammation. Science. 2000;287(5455):104953.

123. Chen J, Tang $\mathrm{H}$, Hay N, Xu J, Ye RD. Akt isoforms differentially regulate neutrophil functions. Blood. 2010;115(21):4237-46.

124. Lorne E, Zhao X, Zmijewski JW, Liu G, Park YJ, Tsuruta Y, et al. Participation of mammalian target of rapamycin complex 1 in Toll-like receptor 2- and 4-induced neutrophil activation and acute lung injury. American journal of respiratory cell and molecular biology. 2009;41(2):237-45.

125. Sathaliyawala T, O'Gorman WE, Greter M, Bogunovic M, Konjufca V, Hou ZE, et al. Mammalian target of rapamycin controls dendritic cell development downstream of Flt3 ligand signaling. Immunity. 2010;33(4):597-606.

126. Lehman JA, Calvo V, Gomez-Cambronero J. Mechanism of ribosomal p70S6 kinase activation by granulocyte macrophage colony-stimulating factor in neutrophils: cooperation of a MEK-related, THR421/SER424 kinase and a rapamycin-sensitive, m-TOR-related THR389 kinase. The Journal of biological chemistry. 2003;278(30):28130-8.

127. Lindemann SW, Yost CC, Denis MM, McIntyre TM, Weyrich AS, Zimmerman GA. Neutrophils alter the inflammatory milieu by signal-dependent translation of constitutive messenger RNAs. Proc Natl Acad Sci U S A. 2004;101(18):7076-81.

128. Fernández N, González A, Valera I, Alonso S, Crespo MS. Mannan and peptidoglycan induce COX-2 protein in human PMN via the mammalian target of rapamycin. Eur J Immunol. 2007;37(9):2572-82.

129. Itakura A, McCarty OJ. Pivotal role for the mTOR pathway in the formation of neutrophil extracellular traps via regulation of autophagy. American journal of physiology Cell physiology. 2013;305(3):C348-54.

130. He Y, Li D, Cook SL, Yoon MS, Kapoor A, Rao CV, et al. Mammalian target of rapamycin and Rictor control neutrophil chemotaxis by regulating Rac/Cdc42 activity and the actin cytoskeleton. Molecular biology of the cell. 2013;24(21):3369-80.

131. Singer M, Deutschman CS, Seymour CW, Shankar-Hari M, Annane D, Bauer M, et al. The Third International Consensus Definitions for Sepsis and Septic Shock (Sepsis-3). JAMA. 2016;315(8):801-10. 132. Bone RC, Balk RA, Cerra FB, Dellinger RP, Fein AM, Knaus WA, et al. Definitions for sepsis and organ failure and guidelines for the use of innovative therapies in sepsis. The ACCP/SCCM Consensus Conference Committee. American College of Chest Physicians/Society of Critical Care Medicine. Chest. 1992;101(6):1644-55. 
133. Levy MM, Fink MP, Marshall JC, Abraham E, Angus D, Cook D, et al. 2001 SCCM/ESICM/ACCP/ATS/SIS International Sepsis Definitions Conference. Critical care medicine. 2003;31(4):1250-6.

134. Silva E, Pedro Mde A, Sogayar AC, Mohovic T, Silva CL, Janiszewski M, et al. Brazilian Sepsis Epidemiological Study (BASES study). Crit Care. 2004;8(4):R251-60.

135. Marik PE, Taeb AM. SIRS, qSOFA and new sepsis definition. J Thorac Dis. 2017;9(4):943-5.

136. Williams JM, Greenslade JH, McKenzie JV, Chu K, Brown AFT, Lipman J. Systemic Inflammatory Response Syndrome, Quick Sequential Organ Function Assessment, and Organ Dysfunction: Insights From a Prospective Database of ED Patients With Infection. Chest. 2017;151(3):586-96.

137. Cohen J. The immunopathogenesis of sepsis. Nature. 2002;420(6917):885-91.

138. Angus DC, van der Poll T. Severe sepsis and septic shock. The New England journal of medicine. 2013;369(9):840-51.

139. Hotchkiss RS, Monneret G, Payen D. Sepsis-induced immunosuppression: from cellular dysfunctions to immunotherapy. Nature reviews Immunology. 2013;13(12):862-74.

140. Deutschman CS, Tracey KJ. Sepsis: current dogma and new perspectives. Immunity. 2014;40(4):463-75.

141. Weber GF, Chousterman BG, He S, Fenn AM, Nairz M, Anzai A, et al. Interleukin-3 amplifies acute inflammation and is a potential therapeutic target in sepsis. Science. 2015;347(6227):1260-5.

142. Yipp BG, Petri B, Salina D, Jenne CN, Scott BN, Zbytnuik LD, et al. Infection-induced NETosis is a dynamic process involving neutrophil multitasking in vivo. Nature medicine. 2012;18(9):1386-93.

143. Fong Y, Tracey KJ, Moldawer LL, Hesse DG, Manogue KB, Kenney JS, et al. Antibodies to cachectin/tumor necrosis factor reduce interleukin 1 beta and interleukin 6 appearance during lethal bacteremia. The Journal of experimental medicine. 1989;170(5):1627-33.

144. Dinarello CA. Infection, fever, and exogenous and endogenous pyrogens: some concepts have changed. Journal of endotoxin research. 2004;10(4):201-22.

145. Chai Z, Gatti S, Toniatti C, Poli V, Bartfai T. Interleukin (IL)-6 gene expression in the central nervous system is necessary for fever response to lipopolysaccharide or IL-1 beta: a study on IL-6deficient mice. The Journal of experimental medicine. 1996;183(1):311-6.

146. Riedemann NC, Neff TA, Guo RF, Bernacki KD, Laudes IJ, Sarma JV, et al. Protective effects of IL-6 blockade in sepsis are linked to reduced C5a receptor expression. J Immunol. 2003;170(1):503-7.

147. Kluger MJ. Fever: role of pyrogens and cryogens. Physiological reviews. 1991;71(1):93-127.

148. Romanovsky AA, Almeida MC, Aronoff DM, Ivanov Al, Konsman JP, Steiner AA, et al. Fever and hypothermia in systemic inflammation: recent discoveries and revisions. Frontiers in bioscience : a journal and virtual library. 2005;10:2193-216.

149. Tavares-Murta BM, Zaparoli M, Ferreira RB, Silva-Vergara ML, Oliveira CH, Murta EF, et al. Failure of neutrophil chemotactic function in septic patients. Critical care medicine. 2002;30(5):105661.

150. Benjamim CF, Ferreira SH, Cunha FQ. Role of nitric oxide in the failure of neutrophil migration in sepsis. The Journal of infectious diseases. 2000;182(1):214-23.

151. Alves-Filho JC, de Freitas A, Russo M, Cunha FQ. Toll-like receptor 4 signaling leads to neutrophil migration impairment in polymicrobial sepsis. Critical care medicine. 2006;34(2):461-70.

152. ter Meulen J, Sakho M, Koulemou K, Magassouba N, Bah A, Preiser W, et al. Activation of the cytokine network and unfavorable outcome in patients with yellow fever. The Journal of infectious diseases. 2004;190(10):1821-7.

153. Ozbalkan Z, Aslar AK, Yildiz Y, Aksaray S. Investigation of the course of proinflammatory and anti-inflammatory cytokines after burn sepsis. International journal of clinical practice. 2004;58(2):125-9.

154. Alves-Filho JC, Spiller F, Cunha FQ. Neutrophil paralysis in sepsis. Shock. 2010;34 Suppl 1:1521.

155. Babior BM. Phagocytes and oxidative stress. The American journal of medicine. 2000;109(1):33-44. 
156. Clark SR, Ma AC, Tavener SA, McDonald B, Goodarzi Z, Kelly MM, et al. Platelet TLR4 activates neutrophil extracellular traps to ensnare bacteria in septic blood. Nature medicine. 2007;13(4):463-9.

157. Xu J, Zhang X, Pelayo R, Monestier M, Ammollo CT, Semeraro F, et al. Extracellular histones are major mediators of death in sepsis. Nature medicine. 2009;15(11):1318-21.

158. McDonald B, Urrutia R, Yipp BG, Jenne CN, Kubes P. Intravascular neutrophil extracellular traps capture bacteria from the bloodstream during sepsis. Cell host \& microbe. 2012;12(3):324-33.

159. Luo L, Zhang S, Wang Y, Rahman M, Syk I, Zhang E, et al. Proinflammatory role of neutrophil extracellular traps in abdominal sepsis. American journal of physiology Lung cellular and molecular physiology. 2014;307(7):L586-96.

160. Brown KA, Brain SD, Pearson JD, Edgeworth JD, Lewis SM, Treacher DF. Neutrophils in development of multiple organ failure in sepsis. Lancet. 2006;368(9530):157-69.

161. Dhainaut JF, Marin N, Mignon A, Vinsonneau C. Hepatic response to sepsis: interaction between coagulation and inflammatory processes. Critical care medicine. 2001;29(7 Suppl):S42-7.

162. Hakkim A, Furnrohr BG, Amann K, Laube B, Abed UA, Brinkmann V, et al. Impairment of neutrophil extracellular trap degradation is associated with lupus nephritis. Proceedings of the National Academy of Sciences of the United States of America. 2010;107(21):9813-8.

163. Borissoff JI, Joosen IA, Versteylen MO, Brill A, Fuchs TA, Savchenko AS, et al. Elevated levels of circulating DNA and chromatin are independently associated with severe coronary atherosclerosis and a prothrombotic state. Arteriosclerosis, thrombosis, and vascular biology. 2013;33(8):2032-40.

164. Saffarzadeh M, Juenemann C, Queisser MA, Lochnit G, Barreto G, Galuska SP, et al. Neutrophil extracellular traps directly induce epithelial and endothelial cell death: a predominant role of histones. PloS one. 2012;7(2):e32366.

165. Chen X, Lee KA, Ren X, Ryu JC, Kim G, Ryu JH, et al. Synthesis of a highly HOCl-selective fluorescent probe and its use for imaging $\mathrm{HOCl}$ in cells and organisms. Nat Protoc. 2016;11(7):121928.

166. Robinson KM, Janes MS, Pehar M, Monette JS, Ross MF, Hagen TM, et al. Selective fluorescent imaging of superoxide in vivo using ethidium-based probes. Proceedings of the National Academy of Sciences of the United States of America. 2006;103(41):15038-43.

167. Sarbassov DD, Guertin DA, Ali SM, Sabatini DM. Phosphorylation and regulation of Akt/PKB by the rictor-mTOR complex. Science. 2005;307(5712):1098-101.

168. Powell JD, Pollizzi KN, Heikamp EB, Horton MR. Regulation of immune responses by mTOR. Annu Rev Immunol. 2012;30:39-68.

169. Qin X, Jiang B, Zhang Y. 4E-BP1, a multifactor regulated multifunctional protein. Cell Cycle. 2016;15(6):781-6.

170. Rozenberg-Arska M, Salters ME, van Strijp JA, Geuze JJ, Verhoef J. Electron microscopic study of phagocytosis of Escherichia coli by human polymorphonuclear leukocytes. Infect Immun. 1985;50(3):852-9.

171. Sônego F, Castanheira FV, Ferreira RG, Kanashiro A, Leite CA, Nascimento DC, et al. Paradoxical Roles of the Neutrophil in Sepsis: Protective and Deleterious. Front Immunol. 2016;7:155.

172. Li JL, Li G, Jing XZ, Li YF, Ye QY, Jia HH, et al. Assessment of clinical sepsis-associated biomarkers in a septic mouse model. J Int Med Res. 2018;46(6):2410-22.

173. Pierrakos C, Vincent JL. Sepsis biomarkers: a review. Crit Care. 2010;14(1):R15.

174. Calandra T, Baumgartner JD, Grau GE, Wu MM, Lambert PH, Schellekens J, et al. Prognostic values of tumor necrosis factor/cachectin, interleukin-1, interferon-alpha, and interferon-gamma in the serum of patients with septic shock. Swiss-Dutch J5 Immunoglobulin Study Group. J Infect Dis. 1990;161(5):982-7.

175. Riché F, Panis Y, Laisné MJ, Briard C, Cholley B, Bernard-Poenaru O, et al. High tumor necrosis factor serum level is associated with increased survival in patients with abdominal septic shock: a prospective study in 59 patients. Surgery. 1996;120(5):801-7.

176. Wang $\mathrm{CH}$, Gee MJ, Yang C, Su YC. A new model for outcome prediction in intra-abdominal sepsis by the linear discriminant function analysis of IL- 6 and IL-10 at different heart rates. J Surg Res. 2006;132(1):46-51. 
177. Marchant A, Alegre ML, Hakim A, Piérard G, Marécaux G, Friedman G, et al. Clinical and biological significance of interleukin-10 plasma levels in patients with septic shock. J Clin Immunol. 1995;15(5):266-73.

178. Pinsky MR, Vincent JL, Deviere J, Alegre M, Kahn RJ, Dupont E. Serum cytokine levels in human septic shock. Relation to multiple-system organ failure and mortality. Chest. 1993;103(2):565-75.

179. Wu HP, Chen CK, Chung K, Tseng JC, Hua CC, Liu YC, et al. Serial cytokine levels in patients with severe sepsis. Inflamm Res. 2009;58(7):385-93.

180. Bozza FA, Salluh JI, Japiassu AM, Soares M, Assis EF, Gomes RN, et al. Cytokine profiles as markers of disease severity in sepsis: a multiplex analysis. Crit Care. 2007;11(2):R49.

181. Patel RT, Deen KI, Youngs D, Warwick J, Keighley MR. Interleukin 6 is a prognostic indicator of outcome in severe intra-abdominal sepsis. Br J Surg. 1994;81(9):1306-8.

182. Jansen PM, van Damme J, Put W, de Jong IW, Taylor FB, Hack CE. Monocyte chemotactic protein 1 is released during lethal and sublethal bacteremia in baboons. J Infect Dis. 1995;171(6):16402.

183. Kurt AN, Aygun AD, Godekmerdan A, Kurt A, Dogan Y, Yilmaz E. Serum IL-1beta, IL-6, IL-8, and TNF-alpha levels in early diagnosis and management of neonatal sepsis. Mediators Inflamm. 2007;2007:31397.

184. Shanley TP, Schmal H, Warner RL, Schmid E, Friedl HP, Ward PA. Requirement for C-X-C chemokines (macrophage inflammatory protein-2 and cytokine-induced neutrophil chemoattractant) in IgG immune complex-induced lung injury. J Immunol. 1997;158(7):3439-48.

185. Andreucci M, Faga T, Pisani A, Perticone M, Michael A. The ischemic/nephrotoxic acute kidney injury and the use of renal biomarkers in clinical practice. Eur J Intern Med. 2017;39:1-8.

186. Irahara T, Sato N, Otake K, Matsumura S, Inoue K, Ishihara K, et al. Alterations in energy substrate metabolism in mice with different degrees of sepsis. J Surg Res. 2018;227:44-51.

187. Ho KKY. Diet-induced thermogenesis: fake friend or foe? J Endocrinol. 2018;238(3):R185-R91.

188. Matsushima H, Geng S, Lu R, Okamoto T, Yao Y, Mayuzumi N, et al. Neutrophil differentiation into a unique hybrid population exhibiting dual phenotype and functionality of neutrophils and dendritic cells. Blood. 2013;121(10):1677-89.

189. Jenne CN, Liao S, Singh B. Neutrophils: multitasking first responders of immunity and tissue homeostasis. Cell Tissue Res. 2018;371(3):395-7.

190. Liu H, Qiu Y, Xiao L, Dong F. Involvement of protein kinase Cepsilon in the negative regulation of Akt activation stimulated by granulocyte colony-stimulating factor. J Immunol. 2006;176(4):240713.

191. Lee WB, Yan JJ, Kang JS, Chung S, Kim LK. Mycobacterial cord factor enhances migration of neutrophil-like HL-60 cells by prolonging AKT phosphorylation. Microbiol Immunol. 2017;61(12):52330.

192. Lu Y, Wahl LM. Production of matrix metalloproteinase-9 by activated human monocytes involves a phosphatidylinositol-3 kinase/Akt/IKKalpha/NF-kappaB pathway. J Leukoc Biol. 2005; 78(1):259-65.

193. Ribeiro MC, Peruchetti DB, Silva LS, Silva-Filho JL, Souza MC, Henriques MDG, et al. LPS Induces mTORC1 and mTORC2 Activation During Monocyte Adhesion. Front Mol Biosci. 2018;5:67.

194. Anderson KE, Coadwell J, Stephens LR, Hawkins PT. Translocation of PDK-1 to the plasma membrane is important in allowing PDK-1 to activate protein kinase B. Curr Biol. 1998;8(12):684-91.

195. Ma XM, Blenis J. Molecular mechanisms of mTOR-mediated translational control. Nat Rev Mol Cell Biol. 2009;10(5):307-18.

196. Shrestha S, Noh JM, Kim SY, Ham HY, Kim YJ, Yun YJ, et al. Angiotensin converting enzyme inhibitors and angiotensin II receptor antagonist attenuate tumor growth via polarization of neutrophils toward an antitumor phenotype. Oncoimmunology. 2016;5(1):e1067744.

197. Kuwabara WM, Curi R, Alba-Loureiro TC. Autophagy Is Impaired in Neutrophils from Streptozotocin-Induced Diabetic Rats. Front Immunol. 2017;8:24.

198. Cybulski N, Hall MN. TOR complex 2: a signaling pathway of its own. Trends Biochem Sci. 2009;34(12):620-7. 
199. Freeman SA, Grinstein S. Phagocytosis: receptors, signal integration, and the cytoskeleton. Immunological reviews. 2014;262(1):193-215.

200. Schlam D, Bagshaw RD, Freeman SA, Collins RF, Pawson T, Fairn GD, et al. Phosphoinositide 3kinase enables phagocytosis of large particles by terminating actin assembly through Rac/Cdc42 GTPase-activating proteins. Nat Commun. 2015;6:8623.

201. McInturff AM, Cody MJ, Elliott EA, Glenn JW, Rowley JW, Rondina MT, et al. Mammalian target of rapamycin regulates neutrophil extracellular trap formation via induction of hypoxia-inducible factor $1 \alpha$. Blood. 2012;120(15):3118-25.

202. Albrich JM, Hurst JK. Oxidative inactivation of Escherichia coli by hypochlorous acid. Rates and differentiation of respiratory from other reaction sites. FEBS letters. 1982;144(1):157-61.

203. McKenna SM, Davies KJ. The inhibition of bacterial growth by hypochlorous acid. Possible role in the bactericidal activity of phagocytes. The Biochemical journal. 1988;254(3):685-92.

204. Pullar JM, Vissers MC, Winterbourn CC. Living with a killer: the effects of hypochlorous acid on mammalian cells. IUBMB life. 2000;50(4-5):259-66.

205. Pick E. Role of the Rho GTPase Rac in the activation of the phagocyte NADPH oxidase: outsourcing a key task. Small GTPases. 2014;5:e27952.

206. Etienne-Manneville S, Hall A. Rho GTPases in cell biology. Nature. 2002;420(6916):629-35.

207. Di-Poi N, Faure J, Grizot S, Molnar G, Pick E, Dagher MC. Mechanism of NADPH oxidase activation by the Rac/Rho-GDI complex. Biochemistry. 2001;40(34):10014-22.

208. Parker H, Albrett AM, Kettle AJ, Winterbourn CC. Myeloperoxidase associated with neutrophil extracellular traps is active and mediates bacterial killing in the presence of hydrogen peroxide. J Leukoc Biol. 2012;91(3):369-76.

209. Palmer L, Cooper PR, Ling MR, Wright HJ, Huissoon A, Chapple IL. Hypochlorous acid regulates neutrophil extracellular trap release in humans. Clin Exp Immunol. 2012;167(2):261-8.

210. Kaplan MJ, Radic M. Neutrophil extracellular traps: double-edged swords of innate immunity. J Immunol. 2012;189(6):2689-95.

211. Marin-Esteban V, Turbica I, Dufour G, Semiramoth N, Gleizes A, Gorges R, et al. Afa/Dr diffusely adhering Escherichia coli strain C1845 induces neutrophil extracellular traps that kill bacteria and damage human enterocyte-like cells. Infect Immun. 2012;80(5):1891-9.

212. Yuen J, Pluthero FG, Douda DN, Riedl M, Cherry A, Ulanova M, et al. NETosing Neutrophils Activate Complement Both on Their Own NETs and Bacteria via Alternative and Non-alternative Pathways. Front Immunol. 2016;7:137.

213. Liu S, Su X, Pan P, Zhang L, Hu Y, Tan H, et al. Neutrophil extracellular traps are indirectly triggered by lipopolysaccharide and contribute to acute lung injury. Sci Rep. 2016;6:37252.

214. van Raam BJ, Sluiter W, de Wit E, Roos D, Verhoeven AJ, Kuijpers TW. Mitochondrial membrane potential in human neutrophils is maintained by complex III activity in the absence of supercomplex organisation. PLoS One. 2008;3(4):e2013.

215. Lewis AJ, Seymour CW, Rosengart MR. Current Murine Models of Sepsis. Surg Infect (Larchmt). 2016;17(4):385-93.

216. Baker CC, Chaudry IH, Gaines HO, Baue AE. Evaluation of factors affecting mortality rate after sepsis in a murine cecal ligation and puncture model. Surgery. 1983;94(2):331-5.

217. Sekirov I, Russell SL, Antunes LC, Finlay BB. Gut microbiota in health and disease. Physiol Rev. 2010;90(3):859-904.

218. Castaner O, Goday A, Park YM, Lee SH, Magkos F, Shiow STE, et al. The Gut Microbiome Profile in Obesity: A Systematic Review. Int J Endocrinol. 2018;2018:4095789.

219. Phua J, Ngerng W, See K, Tay C, Kiong T, Lim H, et al. Characteristics and outcomes of culturenegative versus culture-positive severe sepsis. Crit Care. 2013;17(5):R202.

220. van Schaik SM, Abbas AK. Role of T cells in a murine model of Escherichia coli sepsis. Eur J Immunol. 2007;37(11):3101-10.

221. Iskander KN, Osuchowski MF, Stearns-Kurosawa DJ, Kurosawa S, Stepien D, Valentine C, et al. Sepsis: multiple abnormalities, heterogeneous responses, and evolving understanding. Physiological reviews. 2013;93(3):1247-88. 
222. Goncalves GM, Zamboni DS, Camara NO. The role of innate immunity in septic acute kidney injuries. Shock. 2010;34 Suppl 1:22-6.

223. Czaikoski PG, Mota JM, Nascimento DC, Sonego F, Castanheira FV, Melo PH, et al. Neutrophil Extracellular Traps Induce Organ Damage during Experimental and Clinical Sepsis. PloS one. 2016;11(2):e0148142.

224. Menegueti MG, de Araújo TR, Laus AM, Martins-Filho OA, Basile-Filho A, Auxiliadora-Martins M. Resting Energy Expenditure and Oxygen Consumption in Critically III Patients With vs Without Sepsis. Am J Crit Care. 2019;28(2):136-41.

225. Ragab F, Sakr Y, Khaled H, Mokhtar S. Oxygen consumption in critically ill patients: the relation between calculation by Fick's principle and measurement by gas-mixing chamber indirect calorimetry. Crit Care.; 2001. p. P134.

226. Granger JI, Ratti PL, Datta SC, Raymond RM, Opp MR. Sepsis-induced morbidity in mice: effects on body temperature, body weight, cage activity, social behavior and cytokines in brain. Psychoneuroendocrinology. 2013;38(7):1047-57.

227. Martin EL, Souza DG, Fagundes CT, Amaral FA, Assenzio B, Puntorieri V, et al. Phosphoinositide3 kinase gamma activity contributes to sepsis and organ damage by altering neutrophil recruitment. Am J Respir Crit Care Med. 2010;182(6):762-73.

228. Alves-Filho JC, Freitas A, Souto FO, Spiller F, Paula-Neto H, Silva JS, et al. Regulation of chemokine receptor by Toll-like receptor 2 is critical to neutrophil migration and resistance to polymicrobial sepsis. Proc Natl Acad Sci U S A. 2009;106(10):4018-23.

229. Rios-Santos F, Alves-Filho JC, Souto FO, Spiller F, Freitas A, Lotufo CM, et al. Down-regulation of CXCR2 on neutrophils in severe sepsis is mediated by inducible nitric oxide synthase-derived nitric oxide. Am J Respir Crit Care Med. 2007;175(5):490-7.

230. Dong G, Song L, Tian C, Wang Y, Miao F, Zheng J, et al. FOXO1 Regulates Bacteria-Induced Neutrophil Activity. Front Immunol. 2017;8:1088.

*Referência Estilo Vancouver 